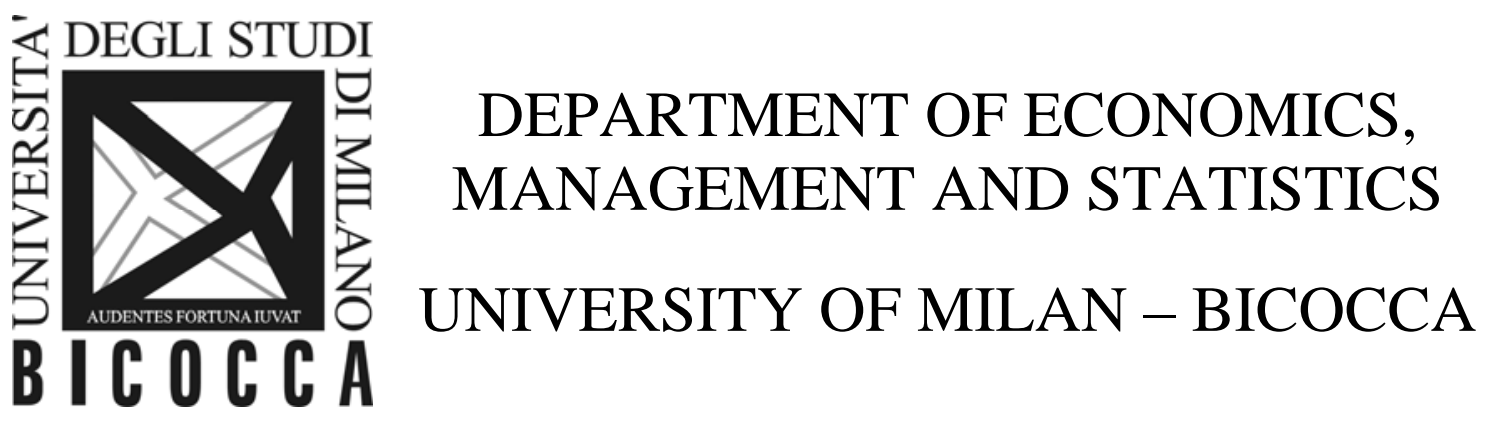

DEMS WORKING PAPER SERIES

\title{
Preferences-dependent learning in the Centipede game
}

Astrid Gamba, Tobias Regner

No. 311 - October 2015

Dipartimento di Economia, Metodi Quantitativi e Strategie di Impresa Università degli Studi di Milano - Bicocca

http://dems.unimib.it/ 


\title{
Preferences-dependent learning in the Centipede game
}

\author{
Astrid Gamba $^{a *}$ Tobias Regner ${ }^{b}$ \\ ${ }^{a}$ University of Milan-Bicocca, Milan, Italy \\ ${ }^{b}$ University of Jena and Max Planck Institute of Economics, Jena, Germany
}

October 2, 2015

\begin{abstract}
We study experimentally whether heterogeneity of behavior in the Centipede game can be interpreted as the result of a learning process of individuals with different preference types (more and less pro-social) and coarse information regarding the opponent's past behavior. We manipulate the quality of information feedbacks provided after each play. If subjects rely only on their personal database, long run behavior resembles a Self-confirming equilibrium whereby less pro-social types take at earlier nodes due to prediction errors. Aggregate information release decreases heterogeneity of behavior by increasing the passing rates of pro-selfs and play moves towards Bayesian Nash equilibrium.
\end{abstract}

JEL classifications: C71, C73, C91, D83

Keywords: social preferences, learning, Self-confirming equilibrium, experiment

${ }^{*}$ Corresponding author (Department of Economics, Management and Statistics, University of Milan-Bicocca, Piazza dell'Ateneo Nuovo 1, 2016, Milan, Italy. Phone: +390264483092. E-mail: astrid.gamba@unimib.it). 


\section{Introduction}

In many strategic interactions, the level of uncertainty that players face about the opponent's behavior might depend on their preferences. Preferences drive behavior which in turn determines what players observe and learn about the opponent's play. This is especially true in contexts where players move sequentially and have access only to statistics regarding plays of opponents they personally met. In such situations, prediction errors about the opponent's behavior at off-path decision nodes may persist in equilibrium and heterogeneous behavior is typically observed. In this paper, we study experimentally how exogenous provision of aggregate information about opponents' past plays affects outcomes of recurrent interactions between agents endowed with different social preferences. For this purpose, we use a modified version of the Centipede game (Rosenthal, 1981).

A common finding in the Centipede game is that some experimental subjects unravel as standard theory predicts, while others do not and few even play cooperatively at the last node. McKelvey and Palfrey (1992) interpret this heterogeneity through a model of incomplete information with heterogeneous preferences whereby few altruists always pass and selfish types mimic them to earn more.

However, this explanation is at odds with recent evidence in Cox and James (2012) who show that behavior in the Centipede game depends on how the game is presented. Changes in the dynamic structure of the game or in its representation that do not affect payoffs generate different outcomes. ${ }^{1}$ This result suggests that uncertainty about the opponent's node-specific play might explain the absence of unraveling in the standard sequential version of the Centipede game. Cox and James (2012) relate to Analogy Based Expectation Equilibrium (ABEE), introduced by Jehiel (2005), where players have coarse conjectures about the oppo-

\footnotetext{
${ }^{1}$ In particular, in the tree format where at each node both players are active and have to decide whether to Take or Leave within a time limit, experimental subjects exhibit more unraveling than in the standard format where players move one at a time along the game tree.
} 
nent's node specific behavior, as a possible candidate to interpret their result. Most importantly, they emphasized that "exploration of the impact of exogenously varied provision of information on past play [...] could help further establish the suitability of candidate explanatory models".

Our study contributes to this research agenda and provides an interpretation of heterogeneous behavior in the Centipede game that is based both on social preferences and strategic uncertainty. Previous studies only assumed the existence of altruistic types in the population of agents active at the last node in order to rationalize the failure of the unraveling prediction. Still, the literature did not consider how social concerns effectively contribute to explain heterogeneity of behavior in this strategic setting. Our study fills this gap. We elicit social preferences in a separate test and and study how the quality of information feedbacks about the opponent's past play affects behavior of different preference types, pro-self and pro-social.

To describe long run outcomes of recurrent interactions between heterogeneous agents, we adopt the solution concept of Self-confirming equilibrium (SCE). We adapt to an extensive-form game the version of SCE proposed by Dekel, Fudenberg and Levine (2004). ${ }^{2}$ SCE essentially describes situations where players choose best replies to conjectures about the opponents' play that may actually be incorrect but consistent with the evidence players can collect ex post, after the choices are made. ${ }^{3}$ In our version of SCE, different preference types interact and best respond to their heterogeneous and possibly incorrect beliefs about the opponent's play. This SCE is appropriate to describe stationary states of an adaptive process resulting from individual learning, whereby individuals with different preferences and possibly different initial beliefs, accumulate different evidence about the opponent's behavior by behaving differently.

\footnotetext{
${ }^{2}$ This version of SCE is similar to the notion of 'conjectural equilibrium' introduced by Battigalli (1987) and Battigalli and Guaitoli (1997).

${ }^{3}$ Notice that, as an ABEE, SCE allows for incorrect beliefs but it is weaker than ABEE as it does not assume that conjectures have a specific structure (i.e., analogy classes).
} 
Gamba (2013) provides an evolutionary foundation for altruistic preferences in a three-stage Centipede game which is based on the SCE play between selfish and altruistic types with type-dependent beliefs. Due to altruists' regard for the opponent's payoff, they always pass money to the opponent (independently on their beliefs) and, when they meet other altruists, they reach the efficient outcome. Due to their lack of trust, selfish types do not pass money to the opponent frequently enough and prevent themselves from learning whether the opponent is actually trustworthy. Hence, their possibly erroneous beliefs persist in equilibrium and so does heterogeneity of behavior across types.

The present paper builds on the Gamba (2013) evolutionary argument and focuses on the learning process that occurs within a single state of the slower evolution of preferences. We assume that the heterogeneity of behavior that we observe in a typical stationary state is due both to strategic uncertainty as suggested by Cox and James (2012) and to the presence of pro-social types, as suggested by McKelvey and Palfrey (1992), but also to the interaction between the two. Indeed, prediction errors alone, that may derive from limited access to information about past play, may explain why we do not observe unraveling in general. However, social preferences may explain heterogeneity in passing rates across individuals. Indeed, besides having a direct effect on behavior, preferences may also influence the information that players collect about the opponent's play. Stopping at earlier nodes delivers less informative feedbacks. ${ }^{4}$

We compare type-specific behavior under different ex post information structures, whereby players receive information feedbacks about the opponent's play that either depend or not on their own behavior. In particular, we elicited social preferences one week before the experiment online through the Social Value Orientation (Murphy, Ackermann and Handgraaf, 2011). In the lab, subjects play anonymously the Centipede game for 40 rounds. We manipulate access to aggregate

\footnotetext{
${ }^{4}$ Trivially, if the first mover stops the game immediately, he receives a feedback that is completely uninformative about the co-player's behavior at later nodes.
} 
statistics on the opponent's past behavior in order to make feedbacks less endogenous or not endogenous at all with respect to their own play. Our 2x2 design varies the elicitation method (DIRECT vs. STRATEGY) and the subjects' information about behavior of their counterparts (PERSONAL vs. PUBLIC). In DIRECT, players move sequentially, while in STRATEGY players choose their strategies simultaneously. We thus implement three different levels of ex post information structure: when subjects' knowledge is limited to their own experiences (PERSONAL), when subjects get information about others' past average choices at each node (PUBLIC-DIRECT) and when they get information about others' past average strategies (PUBLIC-STRATEGY).

We find that aggregate information release increases cooperation in general, independently of the elicitation method. Behavior differs significantly across social preference types only in STRATEGY as pro-social types take at later nodes than pro-selfs. Provision of exogenous feedbacks reduces heterogeneity of behavior across types, due to the increase in pro-selfs' passing rates. At the individual level, there is a negative interaction between preferences and information: the lower the concern for the payoff of the other, the larger the effect of ex post information. On top of this, selfish types are more sensitive to public information in STRATEGY than in DIRECT, i.e., when they are informed about strategies and not actions played, on average, by their opponents.

Among experiments on the Centipede game, the most closely related to ours are Huck and Jehiel (2004) and Maniadis (2010). Huck and Jehiel (2004) studies the impact of incorrect beliefs on play in the Centipede game by manipulating node specific information about the opponent's behavior. They study how players make use of different statistics, more and less precise. If players bundle information sets into analogy classes as in an ABEE (Jehiel, 2005) then facilitating access to nodespecific statistics of play of the opponent should accelerate revision of such coarse conjectures and thus unraveling. They find that players make actually good use of their own past experiences at specific information sets and exogenous provision 
of public information crowds in the use of private statistics.

Maniadis (2010) studies experimentally the effect of aggregate information release on long run behavior in a Centipede game á la McKelvey and Palfrey (1992). In line with the Fudenberg and Levine (1993a) intuition that heterogeneous beliefs play an important role in dynamic games, Maniadis (2010) shows that varying the ex post information structure has a significant effect on long run behavior. Whether aggregate information implies more or less unraveling depends on the payoff structure.

The paper is organized as follows. In the next section we provide the theoretical framework and the learning interpretation. Section 3 describes design, hypotheses and procedures of the experiment; in section 4 we present the experimental results; section 5 discusses and concludes.

\section{Theoretical framework}

Consider a two-player extensive-form game like the Centipede game. Assume that for each player (i.e., role) $i=1,2$ there is a large population of agents with heterogeneous preferences. Each agent has a preference type $\theta \in[0,1]$. Denote $q_{i}(\theta)$ the share of preference type $\theta$ in population $i$. Agents are drawn at random to play the stage game and each agent plays a pure strategy $s_{i, \theta} \in S_{i}$. Hence, each player (role) $i$ plays a mixed strategy $\sigma_{i} \in \Delta\left(S_{i}\right)$, induced by $q_{i}$ and the pure strategies adopted by each preference type in $i$ 's role. We allow agents in population $i$ to have heterogeneous conjectures on the opponent $j$ 's (mixed) strategy: $\mu_{i, \theta} \in \Delta\left(S_{j}\right)$. Assume that agents do not know the distribution of preference types in either population. Denote $\pi\left(z \mid s_{i, \theta} ; \sigma_{j}\right)$ the objective probability that preference type $\theta$ in population $i$ observes terminal node $z$ given his own move and the mixed strategy of the opponent. Denote $\rho\left(z \mid s_{i, \theta} ; \mu_{i, \theta}\right)$ the subjective probability of observing terminal node $z$ as assessed by preference type $\theta$ in population $i$ given his own strategy and his conjecture about the opponent's mixed strategy. Assume that after having played 
agents can only observe the terminal node reached in their own match. We adopt the following definition of Self-confirming equilibrium of an extensive-form game with heterogeneous preference types.

Definition 1 A profile of mixed strategies $\left(\sigma_{i}\right)_{i \in I}$ is a self-confirming equilibrium if for each preference type $\theta$ we can find a conjecture $\mu_{i, \theta}$ s.t. for each $s_{i, \theta} \in$ supp $\sigma i$

i) $s_{i, \theta} \in \arg \max _{s_{i} \in S_{i}}\left[\sum_{s_{j} \in S_{j}} \mu_{i, \theta}\left(s_{j}\right) U_{\theta}\left(s_{i, \theta}, s_{j}\right)\right]$ and

ii) $\forall z \in Z, \rho\left(z \mid s_{i, \theta} ; \mu_{i, \theta}\right)=\pi\left(z \mid s_{i, \theta} ; \sigma\right)$.

The first condition is the standard rationality assumption (players maximize their perceived expected utility); the second condition requires that for each individual that statistical distribution of observations over terminal histories coincides with his subjective probability distribution.

\subsection{Learning interpretation}

The SCE that we have defined can be seen as the result of a learning process whereby different preference types interact recurrently and anonymously and learn about the opponent's behavior only from their own experiences. Fudenberg and Levine (1993b) provides a steady state learning foundation for SCE for static games. ${ }^{5}$ We adapt this interpretation to our extensive form game with heterogeneous agents.

For each role there is a large population of agents playing recurrently the Centipede game. In every round agents are drawn at random and matched to play the stage game with a different co-player. After each play an agent obtains feedbacks on the co-player's play and on the basis of all feedbacks collected in his own matches he updates his beliefs via Bayes' rule. What is crucial is that agents have ex post perfect recall (Battigalli et al., 2015), i.e., after having played they remember the

\footnotetext{
${ }^{5}$ On the learning foundation of SCE, see also Fudenberg and Kreps (1995).
} 
opponent's decision nodes that they have reached and the actions played by the opponent at those nodes. In addition, assume that agents believe that the opponents are playing according to a stationary distribution, as in a fictitious play learning model (Brown, 1951). If there are restrictions to the evidence agents can collect (feedbacks are not informative enough), long-run frequencies of personal observations do not unambiguously identify the objective distribution of the opponent's play. Hence, it can occur that agents hold beliefs that are consistent with the empirical frequencies that they have observed (due to ex post perfect recall) but misrepresent the true distribution (due to uninformative feedbacks).

Assume that agents have access only to their 'personal' database of experiences, that consist of terminal nodes reached in the games they played. If agents do not experiment enough, the learning process will deliver a SCE with heterogeneous and possibly incorrect beliefs. ${ }^{6}$ Alternatively, assume that agents have access also to a 'public' database of terminal nodes reached in all games played by agents in their own population. In the long run we would have a SCE with unitary beliefs, as the justifying belief is the same for all pure strategies $s_{i}$ in the support of the mixed strategy $\sigma_{i}$ (i.e., for all strategies played by each agent in population $i$ ). ${ }^{7}$

Personal experiences allow agents to learn the conditional frequencies of opponent's actions at the opponent's information sets (decision nodes) visited with positive frequency under $\left(s_{i}, \sigma_{j}\right)$, a sub-collection of the opponent's information set visited with positive frequency under $\left(\sigma_{i}, \sigma_{j}\right)$. Given that the individual strat-

\footnotetext{
${ }^{6}$ Players' long run conjectures and behavior will strongly depend on their own past behavior. Trivially, if a player starts the learning process with no trust toward the opponent and keeps stopping the game at the very first node, his conjectures will keep being confirmed by the evidence. Hence, he will never learn whether there are agents who actually behave more cooperatively than he expected and, if there are, he will keep behaving sub-optimally.

${ }^{7}$ Notice that a Self-confirming equilibrium with unitary independent beliefs (same beliefs about the opponent's off-path behavior) and observable deviators is observationally equivalent to a Nash equilibrium. However, the assumption on observable deviators is not satisfied in our context, hence we cannot use this theoretical result to predict that with public information (thus, unitary beliefs) there is outcome equivalence.
} 
egy $s_{i}$ depends on the individual's preference type, the information collected is endogenous and depends on the individual's type. When agents have access to the public database, how much agents playing in role $i$ can learn about the opponent $j$ 's strategy depends on the distribution of preference types in population $i$ that determines $\sigma_{i}$.

Notice that unitary beliefs on the mixed strategy of the opponent $\sigma_{j}$ do not need to be correct as, even with public information, agents playing in $i$ 's role may not observe the off-path intended play of $j$ under $\sigma_{i}$.

Finally, if we assume that agents have access to a 'public' database of strategies played on average in the opponent's population, then beliefs about the mixed strategy of the opponent need to be correct and long run play would correspond to a Bayesian Nash equilibrium.

\section{Experimental design}

Our study is set up to analyze the relationship between preferences and learning. A week before the actual experiment subjects were asked to fill in the social value orientation slider measure (Murphy, Ackermann and Handgraaf, 2011) via an online platform. This provides us with a general measure of subjects' social preferences. In the first part of the experiment, subjects play a mini trust game which measures their preferences in a game-specific context. In the second part, they play a Centipede game for 40 rounds.

The experimental design varies the extent and type of information subjects can obtain about the co-player's behavior after playing. We implement three different levels of ex post information structure by varying two design factors: the information subjects receive about behavior of their counterparts (personal vs. public) and the way we elicited behavior (direct response vs. strategy method). In the PERSONAL condition, subjects only observe the terminal nodes reached in their own matches. In the PUBLIC-DIRECT treatment, aggregate information on av- 
erage behavior (conditional frequencies of actions) of the opponent is provided. Finally, in the PUBLIC-STRATEGY treatment, aggregate information is about frequencies of strategies chosen by the opponents. This allows us to analyze the interplay between information about others' choices and preferences.

Moreover, we elicit subjects' beliefs about average opponents' choices (four times over the course of the game). Subjects' payment from the experiment was announced at the very end of the experiment and consisted of the payoff from part 1 , the payoff from two randomly chosen rounds of part 2 (one from the first 20, one from the last 20), and earnings from the estimations (all were paid). Instructions for part 2 of the experiment were distributed after subjects completed part 1. See the appendix for instructions of the experiment.

\subsection{Preferences elicitation}

We elicited social preferences and classified subjects into preferences types in the following way. First, a week before the experiment we administered the Social Value Orientation (SVO) test (Murphy, Ackermann and Handgraaf, 2011). ${ }^{8}$ We use the SVO measure as a proxy for subjects' concern for the payoff of the other. Second, in the experiment subjects play a mini trust game with choices being elicited using the strategy method (see appendix B for more details). The strategic context of this game features the same tension between joint payoff maximization and selfish motives that we find in the Centipede game. When the trustor sends money to the trustee the pie gets bigger but, if the trustee does not reciprocate, the trustor receives less than what he could have received by keeping the money in the first place.

We combine the two methods and use choices in the mini trust game to check how

\footnotetext{
${ }^{8}$ Essentially, the SVO test computes the average monetary payoff allocated to self $\left(\pi_{s}\right)$ and the average monetary payoff allocated to the other person $\left(\pi_{o}\right)$. It determines the ratio $\frac{\pi_{s}-50}{\pi_{o}-50}$ and computes the inverse tangent of this ratio and the corresponding angle degree.
} 
meaningful the SVO measure is in a strategic context similar to the Centipede game. We normalize the SVO angle to get a parameter $\theta \in[0,1]$ and establish a threshold for $\theta$ above which types are categorized as pro-social and below as pro-self. This threshold $(\theta=0.6)$ is based on performance in predicting behavior in the mini trust game.

\subsection{The experimental game}

We adopt a particular version of the six-stages Centipede game (CG) with a payoff structure which displays the usual tension between selfish motives and efficiency concerns, but differently from the original version it provides high incentives to continue at every decision node. In addition, the arithmetic progression of payoffs from one terminal node to the other make inequity aversion and risk aversion concerns constant across decision nodes.

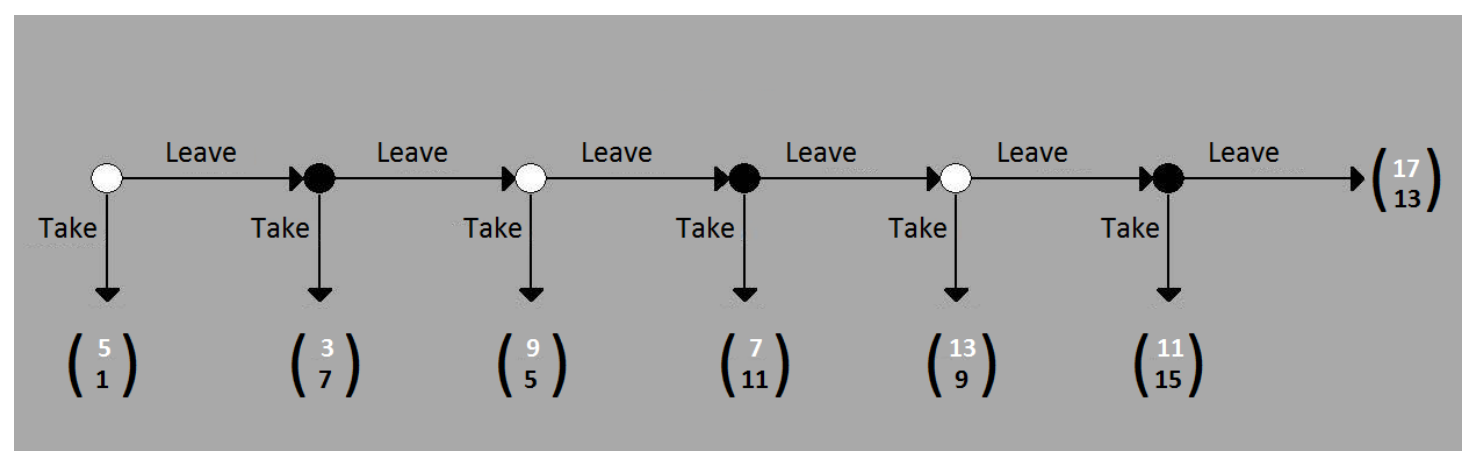

Figure 1: The Centipede game (CG)

Figure 1 illustrates the game tree and the progression of monetary payoffs (denoted in experimental currency units (ECU)). We call White (Black) the player active at white (black) nodes. Subjects are randomly assigned to be either White or Black before the first round of the experiment. As told in the instructions, they keep their role for 40 rounds. In order to minimize reputation concerns we used a rotation matching that ensured that during the first 16 rounds subjects cannot affect the decisions of future subjects they will be paired with through their 
choices in the current match. ${ }^{9}$ Subjects were informed about the protocol and its meaning during the first 16 rounds, that after round 16 they randomly meet other subjects, and that the identity of subjects is never revealed. This approach allowed us to minimize reputation concerns among subjects in a controlled way. Eliminating reputation concerns entirely was not possible in our lab since we decided that studying learning effects required us to play more than 16 rounds (the lab's maximum capacity divided by two).

We employ two different behavior elicitation methods. The first, DIRECT, is the standard direct response method. Subjects play sequentially at alternate nodes until either of the two stops the game by choosing Take. The second, STRATEGY, is a variant of the strategy method (Selten, 1967). Subjects play their strategies simultaneously; in particular, they have to choose at which node they would stop the game independently of the choices of their co-player by picking one of four options: Take at the first node $\left(s^{1}\right)$, Leave at the first and Take at the second node $\left(s^{2}\right)$, Leave at the first and at the second node and Take at the last node $\left(s^{3}\right)$; Leave at all nodes $\left(s^{4}\right)$. They knew they had to choose one of them and that final payoffs for the two matched players White and Black depended on the option choices of both. In this way we elicit their intended way of playing the game. ${ }^{10}$

\subsection{Treatments}

The notion of Self-confirming equilibrium goes along with an explicit definition of the ex-post information structure, that is, what players can observe regarding

\footnotetext{
${ }^{9}$ The 32 subjects of one session were divided into two groups, White and Black. Each of the 16 White subjects was matched with each Black subject exactly once during the first 16 rounds. This allowed us to run 16 rounds of play without interaction or contagion effects. In round 17 the protocol started anew as well as in round 33 .

${ }^{10}$ Notice that the game structure that we call STRATEGY is different from the strategy method introduce by Selten (1967). Indeed, we do not elicit subjects' choices at every decision node of the game tree. So, if for example a subject plays option 2, we do not know how he would behave at the last node in case of crossing it.
} 
outcomes of previous interactions. In a dynamic game, if after playing agents of population $i$ observe only actions played by the agents of population $j$ they have been matched with, heterogeneous beliefs and off-path prediction errors about the opponent $j$ 's strategies may persist in equilibrium. Indeed, the information that any individual receives about the opponent's behavior is endogenous and individual-specific as it depends on the individual's own strategy $s_{i}$. Instead, if after playing agents $i$ observe the actions taken by agents $j$ in all matches, beliefs need to be unitary. Still, they might be incorrect, as they now depend on $\sigma_{i}$, whereas if agents $i$ observe the strategies of agents $j$, their equilibrium beliefs must be unitary and also correct. We are interested in how long run outcomes vary with the ex post information structure, i.e., with the quality of information feedbacks about the opponent's moves after each round of play.

In a first treatment, after playing, subjects are informed about terminal node reached in their own match. We call this treatment PERSONAL, as information feedbacks are individual specific and form the subject's personal database. In another treatment, beside personal information, subjects also receive some aggregate information regarding the opponent's behavior: they are informed about average behavior of subjects playing in the opponent's role, averaged across all matches occurred in the past round. The adoption of the two behavior elicitation methods allows us to vary the informational content of public information feedbacks. When subjects move sequentially (PUBLIC-DIRECT), public feedbacks consist of conditional frequencies of actions played in the past round by all subjects in the opponent's role; when subjects choose simultaneously their strategies (PUBLICSTRATEGY), public feedbacks coincide with the frequencies of strategies played by all subjects in the opponent's population in the round just played. ${ }^{11}$

\footnotetext{
${ }^{11}$ Departing from the population interpretation, in PUBLIC-DIRECT each player receives feedbacks about frequencies of actions actually played by the opponent at information sets that are along the path of play (that are not precluded neither by his own nor by the opponent's strategy). Instead, in PUBLIC-STRATEGY, a player receives feedbacks about frequencies of strategies actually played by his opponent, i.e., about frequencies of actions at information sets
} 
Note that feedbacks are less informative in PUBLIC-DIRECT than in PUBLICSTRATEGY. In the former, subjects are only informed about the behavior of subjects in the opponent's population at information sets that are along the path of play. Thus, subjects in role $i$ receive feedbacks about average play in population $j$ that are endogenous with respect to how all subjects in role $i$ played the game. In contrast, in PUBLIC-STRATEGY, subjects in role $i$ are informed about how subjects in role $j$ intended to play on average and, thus, receive feedbacks about behavior of $j$ subjects at information sets that have been actually precluded by the strategies played by their own population $i$. Hence, in both PUBLIC-DIRECT and PUBLIC-STRATEGY information feedbacks are exogenous with respect to the agent's play. However, in PUBLIC-STRATEGY information is exogenous also with respect to the play of one's own population. ${ }^{12}$

\subsection{Beliefs}

We asked for subjects' point beliefs about opponents' choices before the first round started and in rounds 17, 18, 19 and 40 after decisions were made. ${ }^{13}$ In PUBLIC, we elicited beliefs before aggregate information about subjects' choices appeared. In DIRECT, Whites (Blacks) are asked to estimate for each of the three decision nodes of Blacks (Whites) the percentage of Blacks (Whites) playing Leave at that node. This provides us with subjects' expectations about the opponent's choice at the next node. In STRATEGY, subjects are asked to estimate the percentages of subjects in the other role selecting strategies $s^{1}, s^{2}, s^{3}$ and $s^{4}$. Subjects received that are not precluded by the opponent's strategy (but may be precluded by his own strategy).

${ }^{12}$ For example, in PUBLIC-DIRECT, subjects playing in White's role, are informed about behavior at the last decision node of Black only if this node is actually reached by a positive fraction of Whites.

${ }^{13}$ Although having beliefs data from all rounds would have been ideal, we decided to elicit beliefs only in a subset of all rounds in order not to overload subjects cognitively. Moreover, the elicitation of beliefs was not announced in the instructions and, hence, came at least to some extent as a surprise. We did this to keep subjects' attention focused on the choices in the game. 
$0.5 \mathrm{ECU}$ for each estimate within $5 \%$ of the actual value.

Notice that in order to compare beliefs elicited in the two conditions we need to derive from beliefs over strategies $\mu_{i}\left(s_{j}\right)$, as elicited in STRATEGY, marginal conditional beliefs about the opponent $j$ 's actions at information sets of $j$ that $i$ expects $j$ to reach with positive probability according to $\mu_{i}(\cdot)$. For example, the probability that $j$ will Leave at his second decision node, as assessed by $i$, $\mu_{i}($ Leave $\mid$ Leave $)$, is equal to $\frac{\mu_{i}\left(s^{3}\right)+\mu_{i}\left(s^{4}\right)}{\mu_{i}\left(s^{2}\right)+\mu_{i}\left(s^{3}\right)+\mu_{i}\left(s^{4}\right)}$, i.e., to the sum of the subjective probabilities of all the strategies that prescribes Leave at the second node over the probability that $j$ will not Take at his first decision node. For both methods, in the remaining of the paper, we call $\mu^{1}\left(\mu^{2}\right.$ and $\left.\mu^{3}\right)$ the marginal conditional belief that the opponent will Leave at his first (second and third) decision node.

\subsection{Hypotheses}

Our first hypothesis concerns the heterogeneity of long run behavior across preference types (selfish vs. pro-social). We expect that once behavior has stabilized in PERSONAL selfish types play less cooperative than pro-social types. Due to their lack of trust, selfish underestimate the frequency of Leave at the last nodes, as they do not collect enough observations about the opponents' behavior at these nodes during the course of the game. Hence, they tend to stop the game earlier than they should resulting in sub-optimal behavior. This is compatible with a Self-confirming equilibrium whereby heterogeneous preference types interact.

H1(heterogeneity) In PERSONAL, once behavior has stabilized, pro-social types tend to Take at later nodes than selfish types (in both methods).

Our main hypothesis concerns the effect of public information release. We expect that in PUBLIC the heterogeneity conjectured in H1 drops down. The release of aggregate information reduces strategic uncertainty and generates common and correct beliefs about opponents' behavior across preference types. In particular, selfish types end up with correct beliefs about the opponent's play at the last de- 
cision nodes and best reply to them. Hence, if there is a positive share of subjects playing Leave at the last decision nodes, they get to learn it and react accordingly by playing Leave more frequently. Furthermore, we expect that there is a negative interaction between information and preferences: the less pro-social a subject is, the larger the effect of public information on behavior. Indeed, since strategic uncertainty mostly affects the behavior of selfish types, aggregate information release is expected to affect more their behavior than pro-socials' behavior whose choices are also driven by social motives. Hence, we expect to observe more cooperation in PUBLIC than in PERSONAL and that this difference mainly comes from selfish types stopping at later nodes when aggregate information is released.

H2 In PUBLIC, subjects take at later nodes than in PERSONAL and heterogeneity of behavior drops down (in both methods).

Public information may have a different effect on the behavior of selfish types across the two elicitation methods due to the following reasoning. According to H1, we expect that on average pro-social types plan to take at later nodes with respect to selfish types. However, in the direct method they may be prevented from doing so by opponents who stop the game early. If $\mathrm{H} 1$ holds true, there are certainly more pro-social than selfish types who would, but cannot, reach late nodes. Thus, feedback in the direct method under-represents the true probability of cooperation at late nodes determined by the real strategies played. Instead, feedback in the strategy method refers to real strategies and, in turn, is more informative about the true share of opponents who would cooperate at late nodes. Therefore, the impact of aggregate information release on selfish types' beliefs and behavior in the strategy method should be stronger than in direct response.

H3 In STRATEGY, the effect of public information feedbacks is stronger than in DIRECT.

Finally, Hypothesis 1 builds on two tests regarding, respectively, initial beliefs and first round behavior. The first hypothesis relates to the existence of a "consensus 
effect" (Ross, Greene and House, 1977), ${ }^{14}$ according to which beliefs about the opponent's behavior depend on preferences and certain preference types expect from the opponent a behavior similar to their own. If initial beliefs display this characteristic and players do not experiment enough, then preferences would affect the entire learning process. For example, if White believes that Black will Take at his first node with sufficiently high probability, he will also Take and if he sticks to this behavior his beliefs will always be confirmed.

H4.1 (consensus effect) In round 1, selfish types tend to have more pessimistic beliefs regarding the strategy of the opponent than pro-social types.

The second hypothesis relates to the direct effect of social preferences on behavior, not filtered through the channel of beliefs and experience.

H4.2(social preferences) In round 1, selfish types behave less cooperatively than pro-social types (controlling for initial beliefs).

\subsection{Participants and Procedures}

We recruited 256 participants among students from various disciplines at the local university using the ORSEE software (Greiner, 2004). In each session gender composition was approximately balanced and subjects took part only in one session. The experiment was programmed and conducted with the software z-Tree (Fischbacher, 2007) and took, on average, 100 minutes. The average earnings in the experiment have been $€ 27.41$ (including a $€ 2.50$ show-up fee and $€ 3$ for completing the online survey preceding the experiment).

Upon arrival at the laboratory subjects were randomly assigned to one of the computer terminals. Each computer terminal is in a cubicle that does not allow communication or visual interaction among the participants. Participants were given time to privately read the instructions and were allowed to ask for clari-

\footnotetext{
${ }^{14}$ See also Engelmann and Strobel (2012) for a discussion of the consensus effect in the economics literature.
} 
fications. In order to check the understanding of the instructions subjects were asked to answer a set of control questions. After all subjects had answered the questions correctly the experiment started. At the end of the experiment subjects were paid in cash according to their performance. Privacy was guaranteed during the payment phase.

\section{Results}

We begin by looking at aggregate behavior in the Centipede game. Then, we analyze node-specific behavior in order to test for treatment effects at the individual level. Finally, we explore the role of beliefs.

\subsection{Aggregate behavior}

We estimate random-effect panel regressions in order to analyze aggregate behavior over time. In

$$
z_{i t}=\alpha+\beta t+\gamma c+v_{i}+\epsilon_{i t}
$$

the terminal node reached by subject $i$ is $z$, round is $t$, a vector of control variables is represented by $c$, the subject-specific error term is $v_{i}$ and the residual is $\epsilon_{i t}$. Only Whites are considered in the regression to avoid double counting. Besides the round number, the regressions include dummies for the experimental conditions. The variable Public equals 1 in the PUBLIC condition and Strategy equals 1 in the STRATEGY condition.

Table 1 reports results for rounds 1-30 (column I), and for rounds 31-40 (column II). During the first 30 rounds of the game the PUBLIC condition dummy is positively correlated with the terminal node reached (significant at the 1\%-level). There is a negative time trend of the terminal node reached in PERSONAL but not in PUBLIC. In the last 10 rounds there are no more time trends, while the positive level effect of the PUBLIC condition persists. 
Table 1: Aggregate behavior over time

\begin{tabular}{lcc}
\hline & \multicolumn{2}{c}{ Terminal node } \\
& I: Rounds 1-30 & II: Rounds 31-40 \\
\hline Public & $0.7727^{* * *}$ & $2.4597^{* * *}$ \\
Strategy & $(0.1311)$ & $(0.6801)$ \\
& 0.0462 & 0.4843 \\
Round & $(0.1311)$ & $(0.6801)$ \\
& $-0.0169^{* * *}$ & -0.0136 \\
Public * Round & $(0.0032)$ & $(0.0162)$ \\
& $0.0301^{* * *}$ & 0.0239 \\
Public * Strategy & $(0.0036)$ & $(0.0186)$ \\
Strategy * Round & -0.2021 & $-0.4062^{*}$ \\
& $(0.1672)$ & $(0.2133)$ \\
Constant & 0.0019 & 0.0149 \\
& $(0.0037)$ & $(0.1863)$ \\
\hline$N$ & $4.8479^{* * *}$ & $4.7653^{* * *}$ \\
\hline
\end{tabular}

Notes: the dependent variable is the terminal node reached in a match in the first 30 rounds (column I) and the last 10 rounds (column II) respectively; standard errors are in parentheses; significance levels are: ${ }^{*} p<0.1 ;{ }^{* *} p<0.05 ;{ }^{* * *} p<0.01$.

Hence, in line with previous Centipede game evidence, we find substantial unraveling when learning possibilities are limited to own experience. While in PERSONAL the average terminal node decreases during rounds 1-30, aggregate behavior stabilizes during the last 10 rounds (mean: 4.26). When subjects are better informed about the opponent's behavior (PUBLIC) the average terminal node is substantially higher, it increases during rounds 1-30, and stabilizes during the last 10 rounds (mean: 5.67).

Furthermore, the dummy for the STRATEGY condition is not significantly different from zero. Overall, subjects do not seem to perceive the game differently in comparison to the DIRECT response version that is conventionally employed to 

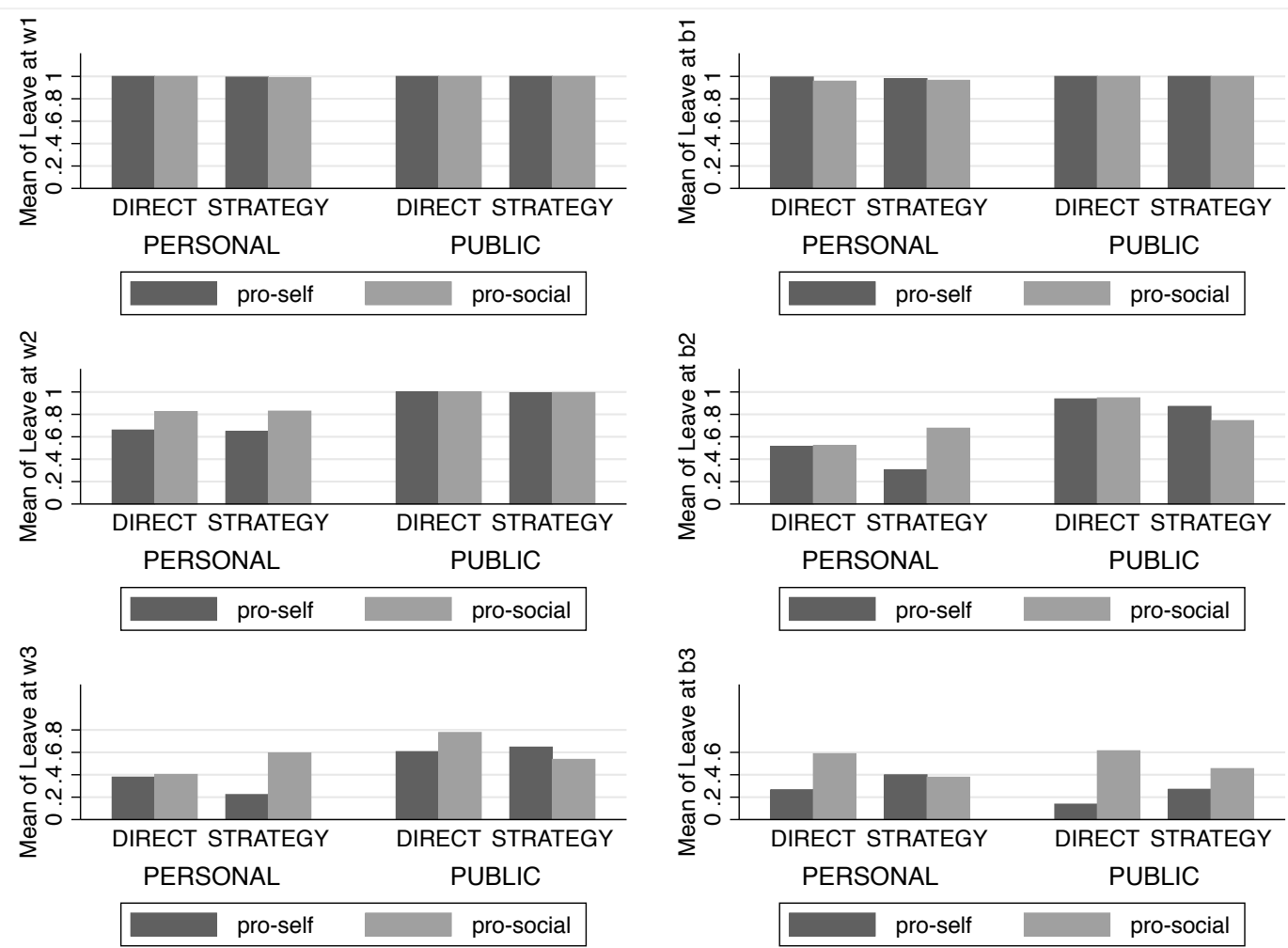

Figure 2: Each of the 6 graphs represents the average frequency of Leave (on the vertical axis) by information treatment, by elicitation method and by preference type at each decision node of the game.

play the Centipede game.

\subsection{Last rounds behavior}

We proceed with a more detailed investigation of choices in the last ten rounds (i.e., when behavior stabilized). Figure 2 shows the average frequency of choosing Leave for each of the six decision nodes of the game (w1, b1, w2, b2, w3, b3). At each node values are provided for the treatments (PERSONAL-DIRECT, PERSONALSTRATEGY, PUBLIC-DIRECT, PUBLIC-STRATEGY) and for the preference types (pro-self and pro-social).

Several behavioral patterns can be observed easily. Virtually all subjects decide 
to Leave at the first two decision nodes (w1, b1), irrespectively of treatment or preference type.

At node w2, all except one subject in PUBLIC play Leave, while in PERSONAL subjects start to Take with positive probability. In PERSONAL-DIRECT the mean is 0.66 for pro-selfs and 0.82 for pro-socials $\left(\chi^{2}\right.$ test: $p<.01 ; 313$ observations). In PERSONAL-STRATEGY the mean is 0.65 for pro-selfs and 0.83 for pro-socials ( $\chi^{2}$ test: $p<.01 ; 317$ observations). Each of these means in PERSONAL is significantly lower than its corresponding counterpart in PUBLIC $\left(\chi^{2}\right.$ tests: $p<.01)$.

Behavior at the second node of Black and at the third node of White (i.e., b2 and w3) is relatively similar. There is a substantial discrepancy across preference types in PERSONAL-STRATEGY. At b2 the mean is 0.31 for pro-selfs and 0.68 for prosocials ( $\chi^{2}$ test: $p<.01 ; 311$ observations) and at w3 the mean is 0.22 for pro-selfs and 0.6 for pro-socials ( $\chi^{2}$ test: $p<.01 ; 234$ observations). In PERSONALDIRECT, we do not find such heterogeneity at b2 and w3, though. The average choice of Leave is essentially equal for pro-selfs and pro-socials. In PUBLIC, averages of Leave at b2 and w3 are generally higher than in PERSONAL. proselfs' means in PUBLIC compared to PERSONAL are 0.94 to 0.51 (DIRECT at b2; 270 observations), 0.87 to 0.31 (STRATEGY at b2; 287), 0.61 to 0.38 (DIRECT at w3; 180) and 0.65 to 0.22 (STRATEGY at w3; 222). All differences are significant at the $1 \%$-level using $\chi^{2}$ tests. Among pro-socials, behavior in PUBLIC and PERSONAL differs only in DIRECT. Pro-socials' means of choosing Leave are 0.95 (PUBLIC) and 0.52 (PERSONAL) at b2 ( $\chi^{2}$ test: $\left.p<.01 ; 282\right)$ and 0.78 and 0.4 at w3 ( $\chi^{2}$ test: $\left.p<.01 ; 242\right)$. In STRATEGY, pro-socials choices do not differ: 0.74 (PUBLIC) and 0.68 (PERSONAL) at b2 ( $\chi^{2}$ test: $p=0.17$; $344), 0.54$ and 0.6 at w3 ( $\chi^{2}$ test: $\left.p=0.3 ; 330\right)$.

Last but not least, behavior at b3, the final node of the game, differs substantially across types as pro-socials tend to Leave more frequently than pro-selfs. In DIRECT pro-socials tend to play Leave more often than pro-selfs, irrespectively of 
the information condition. In PERSONAL the mean is 0.27 for pro-selfs and 0.59 for pro-socials ( $\chi^{2}$ test: $\left.p=0.03 ; 47\right)$ and in PUBLIC it is 0.14 for pro-selfs and 0.61 for pro-socials $\left(\chi^{2}\right.$ test: $\left.p<.01 ; 214\right)$. In STRATEGY, behavior across the preference types is more similar. In PERSONAL the mean is 0.4 for pro-selfs and 0.38 for pro-socials $\left(\chi^{2}\right.$ test: $\left.p=0.8 ; 156\right)$ and in PUBLIC it is 0.27 for pro-selfs and 0.46 for pro-socials $\left(\chi^{2}\right.$ test: $\left.p<.01 ; 256\right)$.

Summarizing behavior, choices of pro-socials and pro-selfs in PERSONAL-STRATEGY differ at middle nodes (b2, w3). In PERSONAL-DIRECT, behavior across preference types is fairly similar at middle nodes but it differs at the last node. ${ }^{15}$

Result 1 In PERSONAL-STRATEGY, behavior in the last 10 rounds is heterogeneous across preference types: pro-social subjects tend to Take at later nodes than pro-self ones.

In PUBLIC, subjects tend to choose Leave more often at middle nodes (w2, b2, w3). This difference is driven by the behavior of pro-selfs as they generally Leave more often in PUBLIC than in PERSONAL. In contrast, pro-socials do not exhibit a higher tendency to Leave in PUBLIC-STRATEGY compared to PERSONALSTRATEGY. As a consequence, in PUBLIC-STRATEGY the heterogeneity of behavior across preference types that we observed in PERSONAL-STRATEGY disappears. Moreover, in PUBLIC pro-socials tend to Leave more often than proselfs at the final node. This difference between preference types is more pronounced in PUBLIC-DIRECT than in PUBLIC-STRATEGY. Analogously to behavior at b3 in PERSONAL, there is a discrepancy between the choices of pro-socials and pro-selfs.

Result 2 In PUBLIC, subjects tend to Leave more often in the last 10 rounds (compared to PERSONAL); this effect is driven by the behavior of pro-selfs.

\footnotetext{
${ }^{15}$ These non-parametric test results are robust to taking the repeated nature and individual heterogeneity into account via panel regression analysis.
} 
To better analyze the effect of aggregate information we compare how far subjects are from optimal behavior (Bayesian Nash) when they have access only to personal statistics and when they have access also to public statistics. In each of the last 10 rounds, we compute the share of subjects in role $i$ who are playing optimally at a certain node given the objective passing rate of the opponent at the next node. We focus on behavior at the most relevant decision nodes b2 and w3, where conjectures about the opponent's strategy are crucial. Given the payoff structure, for a White subject it is optimal to play Leave at w3, independently on his preference type, when the average frequency of Leave at b3 (in that round and session) is larger than $\frac{1}{3} \cdot{ }^{16}$ For a Black subject it is optimal to play Leave at b2 when he plans to Take (Leave) at the last node and the average frequency of Leave at w3 is larger than $\frac{1}{3}\left(\frac{1}{2}\right){ }^{17}$ Tables 2 and 3 report the average shares of subjects (all, pro-socials and pro-selfs) who play Leave at these nodes, in different information treatments, when it is optimal for them to do so.

Data from tables 2 and 3 indicate that when subjects count only on their personal statistics, they play sub-optimally as they do not pass when they should. For example, in DIRECT (table 3), only 32\% (53\%) of all subjects pass at w3 (b2) when it is rational to do so. When public information is released, $71 \%$ (95\%) behave optimally at w3 (b2). Hence, play moves towards Bayesian Nash equilibrium when aggregate information is released. Importantly, in STRATEGY pro-socials are behaving more optimally than pro-selfs. In addition, while knowing the passing rate of the opponent at the next node does not influence much pro-socials' behavior, the share of selfish types who Leave when it is optimal to do so almost doubles at w3 and more than doubles at b2.

\footnotetext{
${ }^{16}$ Notice that this threshold is computed for a totally selfish player maximizing his own material payoff. So if Leave at b3 is larger than this threshold it is certainly optimal for every $\theta$ to Leave at w3.

${ }^{17}$ We cannot say whether in general subjects are playing optimally or sub-optimally as we do have only a proxy $\theta$ for their social preferences.
} 
Table 2: Optimality of behavior across information treatments (STRATEGY)

\begin{tabular}{lcccc}
\hline $\begin{array}{l}\text { Average share of subjects } \\
\text { passing when optimal }\end{array}$ & Personal & Public & Personal & Public \\
\hline \multirow{2}{*}{ All } & .494 & .836 & .433 & .616 \\
& $(.010)$ & $(007)$ & $(.008)$ & $(.007)$ \\
Pro-socials & .659 & .723 & .512 & .625 \\
& $(.028)$ & $(.011)$ & $(.017)$ & $(.012)$ \\
Pro-selfs & .397 & .934 & .350 & .604 \\
& $(.027)$ & $(.009)$ & $(.012)$ & $(.017)$ \\
\hline
\end{tabular}

Notes: this table reports the average shares of Blacks (Whites) playing Leave at their second (third) decision node (i.e., b2 (w3)), when it is optimal to do so given the opponent's behavior at the next node; such shares are averaged across the last 10 rounds, computed by information treatment, for all subjects and by social preference type; standard errors in parentheses.

Table 3: Optimality of behavior across information treatments (DIRECT)

\begin{tabular}{lcccc}
\hline Average share of subjects & \multicolumn{2}{c}{$\mathrm{b} 2$} & \multicolumn{2}{c}{ w3 } \\
passing when optimal & Personal & Public & Personal & Public \\
\hline All & .536 & .947 & .325 & .710 \\
& $(.024)$ & $(.004)$ & $(.025)$ & $(.008)$ \\
Pro-socials & .639 & .960 & .378 & .803 \\
& $(.101)$ & $(.006)$ & $(.053)$ & $(.013)$ \\
Pro-selfs & .574 & .923 & .275 & .571 \\
& $(.030)$ & $(.009)$ & $(.039)$ & $(.019)$ \\
\hline
\end{tabular}

Notes: this table reports the average shares of Blacks (Whites) playing Leave at their second (third) decision node (i.e., b2 (w3)), when it is optimal to do so given the opponent's behavior at the next node; such shares are averaged across the last 10 rounds, computed by information treatment, for all subjects and by social preference type; standard errors in parentheses.

\subsection{Information and behavior}

In order to better understand the effect of aggregate information release on different preference types' behavior, we now consider the effect of information (gained through own experience and public disclosure of aggregate choices) on behavior in our analysis. For this purpose, we run separate random-effect panel regres- 
sions for each node of the game. Table 4 reports results of a set of regressions for PERSONAL-STRATEGY and table 5 for PERSONAL-DIRECT. The dependent variable is whether a subject decided to Take (0) or Leave (1) at a respective node. More specifically, the columns w1 (b1) indicate that choices of Whites (Blacks) at their first decision node, i.e., at node 1 (2) of the game tree, are analyzed, etc. Behavior in any round $t>1$ may depend on observations made up to $t$ about behavior of the opponents. The variable observed behavior represents the personal statistics of a subject, computed at any time $t$ and for all own nodes of the game. It consists of the opponents' average frequency of Leave at the next node out of all own observations made up to $t$. If at $t$ a subject has never observed the opponents' choice at the next node, then observed behavior does not exist. If a subject observed Leave as often as Take, then observed behavior equals 0.5. In

$$
l_{i t}=\alpha+\beta \theta_{i}+\gamma o_{i t}+v_{i}+\epsilon_{i t}
$$

the dependent variable $l$ is whether subject $i$ decided to Take (0) or Leave (1) at a respective node in round $t$, our measure of social preferences is $\theta_{i}$, observed behavior is $o_{i t}$, the subject-specific error term is $v_{i}$ and the residual is $\epsilon_{i t}$.

In PERSONAL-STRATEGY, the main effect of observed behavior is positive and significant at least at the 5\%-level at all nodes except the first of White/Black. Moreover, we find a correlation between $\theta$ and the tendency to Leave at the middle nodes (w2 and b2). The coefficient of the interaction term between $\theta$ and observed behavior is negative and significant at w2 (5\%-level) and b2 (1\%-level). Hence, pro-social types exhibit a tendency to Leave at nodes w2 and b2, irrespectively of the behavior they observe, while selfish types condition their choice to Leave on observed behavior. At node w3 both types tend to rely on the observations they made. 
Table 4: Individual behavior and personal database in PERSONAL-STRATEGY

\begin{tabular}{lccccc}
\hline & $\mathrm{w} 1$ & $\mathrm{~b} 1$ & $\mathrm{w} 2$ & $\mathrm{~b} 2$ & $\mathrm{w} 3$ \\
\hline Observed behavior & -0.052 & 0.537 & $1.194^{* * *}$ & $2.126^{* * *}$ & $1.482^{* *}$ \\
& $(0.057)$ & $(0.391)$ & $(0.407)$ & $(0.409)$ & $(0.673)$ \\
$\theta$ & -0.034 & 0.610 & $1.053^{*}$ & $1.854^{* * *}$ & 0.523 \\
& $(0.064)$ & $(0.486)$ & $(0.540)$ & $(0.524)$ & $(0.412)$ \\
Observed behavior $* \theta$ & 0.029 & -0.666 & $-1.222^{* *}$ & $-2.187^{* * *}$ & -1.135 \\
& $(0.072)$ & $(0.522)$ & $(0.614)$ & $(0.593)$ & $(0.908)$ \\
Constant & $1.046^{* * *}$ & 0.500 & -0.067 & $-0.868^{* *}$ & -0.060 \\
& $(0.049)$ & $(0.365)$ & $(0.364)$ & $(0.348)$ & $(0.261)$ \\
\hline$N$ & 1,280 & 1,264 & 1,245 & 1,112 & 878 \\
\hline
\end{tabular}

Notes: the dependent variables are the choice (Take (0) or Leave (1)) at each decision node of White and Black, in any round $t$ from 2 to 40; in particular, w1 (b1), w2 (b2) and w3 indicate White's (Black's) first, second and third decision node; standard errors in parentheses; significance levels are: ${ }^{*} p<0.1 ; * * p<0.05 ;{ }^{* * *} p<0.01$.

Assuming average observed behavior ${ }^{18}$ and average values of $\theta$ for pro-selfs $(0.4)$ and for pro-socials $(0.75)$, the estimated coefficients mean the following. At w2 a pro-social is not more likely to Leave than a pro-self as the positive main effect of $\theta$ is compensated by the negative interaction effect between $\theta$ and observed behavior. However, at b2 the choice of a pro-social is estimated to be $35 \%$ more likely to be Leave than a pro-self's.

Also in PERSONAL-DIRECT, the main effect of observed behavior is positive and significant at least at the 5\%-level at nodes w2, b2 and w3. Neither $\theta$ nor the interaction term are correlated with the tendency to Leave. It seems that the effect of observed behavior outweighs any effect of the preference type. This is also the case when the interaction term is not included in the regression specification.

\footnotetext{
${ }^{18}$ Average observed behavior in PERSONAL-STRATEGY (over all rounds) is 0.97 at w1 (standard deviation: 0.055$)$, at b1 it is $0.89(0.109)$, at w2 it is $0.64(0.151)$, at b2 it is 0.39 (0.209) and at w3 it is 0.27 (0.28). At the final node (b3) observed behavior is not defined.
} 
Table 5: Individual behavior and personal database in PERSONAL-DIRECT

\begin{tabular}{lccccc}
\hline & $\mathrm{w} 1$ & $\mathrm{~b} 1$ & $\mathrm{w} 2$ & $\mathrm{~b} 2$ & $\mathrm{w} 3$ \\
\hline Observed behavior & -0.018 & -0.053 & $0.757^{* *}$ & $0.788^{* * *}$ & $1.694^{* * *}$ \\
& $(0.014)$ & $(0.081)$ & $(0.342)$ & $(0.207)$ & $(0.531)$ \\
$\theta$ & 0.004 & -0.213 & 0.297 & -0.086 & 0.017 \\
& $(0.014)$ & $(0.164)$ & $(0.571)$ & $(0.303)$ & $(0.325)$ \\
Observed behavior $* \theta$ & 0.018 & 0.211 & -0.154 & 0.143 & -1.388 \\
& $(0.020)$ & $(0.177)$ & $(0.644)$ & $(0.336)$ & $(0.868)$ \\
Constant & $1.000^{* * *}$ & $1.054^{* * *}$ & 0.236 & $0.321^{*}$ & 0.328 \\
& $(0.007)$ & $(0.076)$ & $(0.326)$ & $(0.179)$ & $(0.200)$ \\
\hline \multirow{2}{*}{$N$} & 1,278 & 1,271 & 1,252 & 995 & 505 \\
\hline
\end{tabular}

Notes: the dependent variables are the choice (Take (0) or Leave (1)) at each decision node of White and Black, in any round $t$ from 2 to 40; in particular, w1 (b1), w2 (b2) and w3 indicate White's (Black's) first, second and third decision node; standard errors in parentheses; significance levels are: ${ }^{*} p<0.1{ }^{* *} p<0.05 ;^{* * *} p<0.01$.

In PUBLIC, besides the personal database generated by own observations, there is another source of information. After having played, subjects receive aggregate statistics about how the opponent played the game in that round. This variable, aggregate information, has a different informational content in the two elicitation methods. In DIRECT, it is the average frequency of Leave at any node out of all observations actually made overall, in all matches, up to $t$ at that node. In STRATEGY, it corresponds to the average frequency of Leave at any node out of all choices made overall, in all matches, up to $t$ at that node. ${ }^{19}$ Notice that in STRATEGY a choice made at a certain node by a subject in a given match does not need to coincide with the observation made by the co-player in that match as that node may be off the actual path of play. We incorporate this new variable in the regression sets introduced earlier and report results in table 6 (PUBLIC-

\footnotetext{
${ }^{19}$ Notice that in STRATEGY the exact message that subjects receive consists of the average frequencies of strategies (i.e., stopping nodes) played on average by subjects in the opponent's role. However, for the data analysis, we decomposed average frequencies of strategies into average frequencies of planned actions at nodes compatible with the strategies chosen.
} 
STRATEGY) and in table 7 (PUBLIC-DIRECT).

Table 6: Individual behavior and information in PUBLIC-STRATEGY

\begin{tabular}{lccccc}
\hline & $\mathrm{w} 1$ & $\mathrm{~b} 1$ & $\mathrm{w} 2$ & $\mathrm{~b} 2$ & $\mathrm{w} 3$ \\
\hline Aggregate information & - & 0.037 & -0.107 & $0.538^{* *}$ & $0.723^{* *}$ \\
$\theta$ & - & $(0.036)$ & $(0.116)$ & $(0.257)$ & $(0.315)$ \\
& & 0.005 & 0.004 & -0.164 & -0.147 \\
Observed behavior & - & $(0.005)$ & $(0.012)$ & $(0.121)$ & $(0.245)$ \\
& -0.027 & $0.093^{* *}$ & $0.374^{* * *}$ & $0.443^{* * *}$ \\
Constant & - & $0.987^{* * *}$ & $1.003^{* * *}$ & $0.387^{* *}$ & $(0.114)$ \\
& & $(0.016)$ & $(0.088)$ & $(0.155)$ & $(0.232)$ \\
\hline \multirow{2}{*}{$N$} & - & 1,248 & 1,247 & 1,246 & 1,155 \\
\hline
\end{tabular}

Notes: the dependent variables are the choice (Take (0) or Leave (1)) at each decision node of White and Black, in any round $t$ from 2 to 40; in particular, w1 (b1), w2 (b2) and w3 indicate White's (Black's) first, second and third decision node; standard errors in parentheses; significance levels are: ${ }^{*} p<0.1 ;{ }^{* *} p<0.05 ;{ }^{* *} p<0.01$.

In PUBLIC-STRATEGY, there is a positive correlation (significant at the 5\%level) between aggregate information and the tendency to Leave at nodes b2 and w3. At all nodes except b1 we find a positive correlation between observed behavior and the tendency to Leave (significant at least at the 5\%-level). Alternative regression specifications with an interaction term between aggregate information and $\theta$ or between observed behavior and $\theta$ did not result in significance of the interaction terms lower than the 10\%-level. Comparing the estimated coefficients at b2 and w3, the effect sizes of aggregate information are bigger than the ones of observed behavior but the differences are not statistically significant.

In PUBLIC-DIRECT, there is no correlation between aggregate information and the tendency to Leave. At nodes b2 and w3 the main effects of $\theta$ and observed behavior are positive and significant at least at the 5\%-level. The interaction effect is negative (significant at the $5 \%$-level at b2). It seems that at middle nodes proself types tend to rely on observed behavior, while pro-social types tend to Leave 
Table 7: Individual behavior and information in PUBLIC-DIRECT

\begin{tabular}{lccccc}
\hline & $\mathrm{w} 1$ & $\mathrm{~b} 1$ & $\mathrm{w} 2$ & $\mathrm{~b} 2$ & $\mathrm{w} 3$ \\
\hline Aggregate information & - & 0.022 & 0.033 & 0.074 & 0.497 \\
$\theta$ & - & -0.015 & -0.325 & $0.701^{* *}$ & $0.657^{* *}$ \\
& & $(0.016)$ & $(0.235)$ & $(0.290)$ & $(0.317)$ \\
Observed behavior & - & -0.018 & -0.189 & $1.076^{* * *}$ & $0.919^{* * *}$ \\
& & $(0.019)$ & $(0.148)$ & $(0.188)$ & $(0.206)$ \\
Observed behavior $* 0$ & - & 0.017 & 0.371 & $-0.836^{* *}$ & -0.536 \\
& & $(0.019)$ & $(0.263)$ & $(0.363)$ & $(0.382)$ \\
Constant & - & $0.994^{* * *}$ & $1.136^{* * *}$ & 0.042 & -0.169 \\
& & $(0.009)$ & $(0.129)$ & $(0.183)$ & $(0.242)$ \\
\hline \multirow{2}{*}{$N$} & - & 1,247 & 1,245 & 1,238 & 1,107 \\
\hline
\end{tabular}

Notes: the dependent variables are the choice (Take (0) or Leave (1)) at each decision node of White and Black, in any round $t$ from 2 to 40; in particular, w1 (b1), w2 (b2) and w3 indicate White's (Black's) first, second and third decision node; standard errors in parentheses; significance levels are: ${ }^{*} p<0.1 ;{ }^{* *} p<0.05 ;{ }^{* *} p<0.01$.

irrespectively. As an alternative regression specification we included interaction terms between aggregate information and $\theta$ /observed behavior. However, these interaction terms were not significant.

To summarize, we find that subjects generally internalize observed behavior and react to it, irrespective of the treatment. However, the extent of observed behavior's estimated effect varies across treatments. In PUBLIC-STRATEGY, the effect sizes of observed behavior are relatively small compared to the other treatments. Instead, when subjects are informed about strategies (not only behavior), the effect of aggregate information appears to matter. Moreover, we find that proselfs have a general tendency to respond to observed behavior, while pro-socials tend to Leave irrespective of what they observe (in PERSONAL-STRATEGY and PUBLIC-DIRECT). However, in PERSONAL-DIRECT pro-socials appear to rely on (or are affected by) observed behavior just as pro-selfs. 
Finally, we look at the effects of our information treatments (PUBLIC-DIRECT and PUBLIC-STRATEGY) controlling for observed behavior. We focus on nodes b2 and w3 as behavior at earlier nodes (w1, b1, w2) barely differs and at the last node (b3) information feedback is not available. Besides a specification for all subjects we also report specifications for pro-selfs only and pro-socials only.

Table 8: Treatment effects at nodes b2 and w3

\begin{tabular}{lcccccc}
\hline & & b2 & & & w3 & \\
& all & pro-selfs & pro-socials & all & pro-selfs & pro-socials \\
\hline Public & $0.107^{* * *}$ & $0.144^{* *}$ & $0.081^{* * *}$ & 0.090 & -0.095 & $0.213^{* *}$ \\
& $(0.033)$ & $(0.061)$ & $(0.030)$ & $(0.077)$ & $(0.125)$ & $(0.091)$ \\
Strategy & -0.002 & -0.019 & 0.005 & -0.089 & -0.201 & -0.006 \\
& $(0.045)$ & $(0.084)$ & $(0.043)$ & $(0.090)$ & $(0.142)$ & $(0.114)$ \\
Public * Strategy & -0.001 & 0.013 & -0.008 & 0.066 & $0.355^{* *}$ & -0.132 \\
& $(0.045)$ & $(0.083)$ & $(0.044)$ & $(0.112)$ & $(0.173)$ & $(0.142)$ \\
Observed behavior & 0.034 & -0.003 & $0.057^{* *}$ & $0.575^{* * *}$ & $0.655^{* * *}$ & $0.536^{* * *}$ \\
& $(0.024)$ & $(0.034)$ & $(0.027)$ & $(0.064)$ & $(0.108)$ & $(0.075)$ \\
Constant & $0.877^{* * *}$ & $0.856^{* * *}$ & $0.895^{* * *}$ & $0.388^{* * *}$ & $0.418^{* * *}$ & $0.360^{* * *}$ \\
& $(0.034)$ & $(0.065)$ & $(0.032)$ & $(0.062)$ & $(0.098)$ & $(0.077)$ \\
\hline \multirow{2}{*}{$N$} & 4,352 & 1,927 & 2,425 & 3,673 & 1,608 & 2,065 \\
\hline
\end{tabular}

Notes: the dependent variables are the choice (Take (0) or Leave (1)) at decision nodes b2 and w3, i.e., at the second decision node of Blacks and at the third decision node of Whites; we consider decisions of all subjects but also of pro-selfs and pro-socials on their own; standard errors in parentheses; significance levels are: ${ }^{*} p<0.1 ;{ }^{* *} p<0.05 ;{ }^{* * *} p<0.01$.

At b2 there is a positive main effect of Public (significant at least at the $5 \%$-level). There is no effect of Strategy and the interaction between Public and Strategy is not significant. While observed behavior seems to matter for pro-socials (5\%-level), the coefficient of Public is almost twice the size for pro-selfs than for pro-socials. At w3, considering all subjects, only observed behavior is positively correlated with the tendency to Leave. Looking at pro-selfs and pro-socials separately, we observe no main effects but a positive and significant interaction effect of Public and Strategy for pro-selfs (5\%-level), and a positive main effect of Public for pro- 
socials (significant at the 5\%-level). It appears that at b2 the release of aggregate information about opponents' play has a significant positive effect for pro-selfs as well as for pro-socials and independently of the extent of aggregate information (DIRECT vs. STRATEGY). Pro-socials exhibit such a general tendency to respond to aggregate information also at w3. However, pro-selfs seem to respond to aggregate information at w3 only if they are provided with information about their opponents' strategies (STRATEGY). The provision of information about actions actually played (DIRECT) does not seem to have an effect on their decision to Leave.

Result 3 The effect of information feedback is more pronounced in PUBLICSTRATEGY (at node w3 and for pro-selfs).

\subsection{First round behavior, initial beliefs and preferences}

In order to explore the underlying reasons for the heterogeneity of behavior across preference types, we analyze the relationship between first round choices, initial beliefs and preferences. Table 9 presents results in the same fashion as introduced earlier, that is, the dependent variable is whether a subject decided to Take (0) or Leave (1) at a respective node. As information should not affect behavior in the very first round, we pool data from PERSONAL and PUBLIC, controlling for the elicitation method (dummy variable Strategy) and for the information condition (dummy Public).

While first round choices are not correlated with $\theta$ at the first node of White, we do find significant effects of $\theta$ at the first node of Black (significant at the 1\%-level) and at the second node of White (5\%-level). At the very last node there is a weak correlation between $\theta$ and the tendency to Leave (10\%-level). The coefficients of neither Strategy nor Public are statistically different from zero. These results are in line with our hypothesis that subjects with different concerns for the payoff of others behave differently in our game. However, the effect of social preferences 
Table 9: Individual behavior in round 1

\begin{tabular}{lcccccc}
\hline & $\mathrm{w} 1$ & $\mathrm{~b} 1$ & $\mathrm{w} 2$ & $\mathrm{~b} 2$ & $\mathrm{w} 3$ & $\mathrm{~b} 3$ \\
\hline$\theta$ & 0.069 & $0.342^{* * *}$ & $0.331^{* *}$ & 0.270 & 0.165 & $0.530^{*}$ \\
& $(0.056)$ & $(0.068)$ & $(0.137)$ & $(0.187)$ & $(0.256)$ & $(0.309)$ \\
Strategy & 0.030 & -0.005 & -0.042 & 0.003 & $0.175^{*}$ & -0.003 \\
& $(0.022)$ & $(0.029)$ & $(0.054)$ & $(0.074)$ & $(0.099)$ & $(0.121)$ \\
Public & 0.028 & -0.011 & 0.072 & 0.051 & -0.014 & 0.110 \\
& $(0.022)$ & $(0.029)$ & $(0.054)$ & $(0.074)$ & $(0.098)$ & $(0.112)$ \\
Constant & $0.914^{* * *}$ & $0.772^{* * *}$ & $0.681^{* * *}$ & $0.610^{* * *}$ & $0.408^{* *}$ & -0.057 \\
& $(0.037)$ & $(0.047)$ & $(0.093)$ & $(0.128)$ & $(0.179)$ & $(0.213)$ \\
\hline \multirow{2}{*}{$N$} & 128 & 126 & 124 & 117 & 100 & 72 \\
\hline
\end{tabular}

Notes: the dependent variables are the round 1 choice (Take (0) or Leave (1)) at each decision node of White and Black except the last one; in particular, w1 (b1), w2 (b2) and w3 indicate White's (Black's) first, second and third decision node; standard errors in parentheses; significance levels are: ${ }^{*} p<0.1{ }^{* *} p<0.05 ;{ }^{* *} p<0.01$.

on behavior may be amplified, if preferences also influence initial beliefs (via a consensus effect). As a consequence, preferences-dependent beliefs may determine behavior. In particular, it might be the case that pro-social types have more optimistic beliefs regarding the opponent's behavior (i.e., more trust) and, in turn, stop the game at a later node compared to selfish types. Indeed, we find a positive correlation between $\theta$ and the initial belief at the first (5\%-level) and second node (10\%-level) of White. The finding of a consensus effect (at node 2 of White) warrants further analysis of the relationship between $\theta$, subjects' initial beliefs and the choice to Leave. We find that the effect of $\theta$ on the choice to Leave is partly mediated by subjects' initial belief as the coefficient of $\theta$ is reduced (down from .331 to .244) but still significant at the 5\%-level.

In the set of regressions of table 10 we control for initial beliefs and have also added an interaction term between $\theta$ and the initial belief. In particular, in each regression we estimate the effect that initial (marginal) beliefs that the opponent will play Leave at node $x$ have on the choice to Leave at node $x-1$. The positive 
Table 10: Individual behavior and beliefs in round 1

\begin{tabular}{lccccc}
\hline & $\mathrm{w} 1$ & $\mathrm{~b} 1$ & $\mathrm{w} 2$ & $\mathrm{~b} 2$ & $\mathrm{w} 3$ \\
\hline$\theta$ & $0.922^{* * *}$ & $0.697^{* * *}$ & $0.762^{* *}$ & 0.417 & 0.221 \\
& $(0.267)$ & $(0.183)$ & $(0.310)$ & $(0.255)$ & $(0.370)$ \\
Initial belief & $0.772^{* * *}$ & $0.405^{* *}$ & $1.033^{* * *}$ & $0.941^{* * *}$ & 0.164 \\
& $(0.153)$ & $(0.162)$ & $(0.258)$ & $(0.356)$ & $(0.653)$ \\
$\theta^{*}$ Initial belief & $-1.016^{* * *}$ & $-0.551^{* *}$ & $-0.810^{*}$ & -0.723 & -0.218 \\
& $(0.298)$ & $(0.257)$ & $(0.448)$ & $(0.552)$ & $(1.036)$ \\
Strategy & 0.001 & -0.020 & $-0.130^{* * *}$ & -0.071 & 0.172 \\
\multirow{2}{*}{ Public } & $(0.019)$ & $(0.031)$ & $(0.050)$ & $(0.070)$ & $(0.105)$ \\
& 0.013 & -0.011 & 0.023 & 0.006 & -0.005 \\
Constant & $(0.019)$ & $(0.029)$ & $(0.048)$ & $(0.069)$ & $(0.105)$ \\
& $0.291^{* *}$ & $0.516^{* * *}$ & 0.151 & $0.391 * *$ & 0.363 \\
\hline \multirow{2}{*}{$N$} & $(0.133)$ & $(0.113)$ & $(0.181)$ & $(0.159)$ & $(0.260)$ \\
\hline
\end{tabular}

Notes: the dependent variables are the round 1 choice (Take (0) or Leave (1)) at each decision node of White and Black except the final one (b3); in particular, w1 (b1), w2 (b2) and w3 indicate White's (Black's) first, second and third decision node; standard errors in parentheses; significance levels are: ${ }^{*} p<0.1 ; * *<0.05 ;{ }^{* * *} p<0.01$.

correlation between $\theta$ and the tendency to Leave at nodes b1 and w2 prevails. Generally, initial beliefs have a positive effect on the tendency to Leave. At nodes 1 to 4 the significance level is at least 5\%-level. Only at the last node (w3) the coefficient of the initial beliefs is positive but not significantly different from zero. Besides this positive main effect of the initial beliefs we find a generally negative interaction effect between the initial belief and $\theta$. Coefficients of the interaction term are significant at w1 (1\%-level), b1 (5\%-level) and w2 (10\%-level). It appears that the effect of beliefs is less pronounced for pro-social types than for selfish ones. When pro-socials decide whether to Leave, high beliefs can compensate for the lack of social preferences.

Result 4 In the first round, selfish types have a lower tendency to take at nodes 1 to 3 than pro-socials (unless their initial belief is high). 
Notwithstanding this initial consensus effect, in the last round (i.e., 40), beliefs and preference types are not significantly correlated, see figure 5 (in the Appendix). Comparing figure 2 and 5, we can notice that pro-selfs and pro-socials seem to underestimate the opponent's passing rates in PERSONAL. Still, all subjects appear to have node-specific beliefs about the opponent's behavior. ${ }^{20}$ In the following section, we analyze the effect of information on beliefs, to analyze whether subjects make good use of information feedbacks about the opponent's play, whichever the source of information, endogenous or exogenous.

\subsection{Information and Beliefs}

We now use data from rounds 17 to 19 to analyze the effect of information (gained through own experience and via disclosure of aggregate choices) on beliefs. The dependent variable in each regression is the marginal belief that the opponent will play Leave at a certain decision node. For example, $\mu^{1}$ is the marginal belief elicited in rounds 17-19 that the opponent will play Leave at the first decision node. Table 11 presents regression results.

In PERSONAL, beliefs and observed behavior are highly correlated (except at $\mu^{1}$ ). In PUBLIC, beliefs and aggregate information are highly correlated (except at $\mu^{1}$ ), while the coefficient of observed behavior is also significant (at the 5\%-level). The estimated effect of aggregate information is greater than the one of observed behavior (statistically significant, $p<.01$ ).

Given that observed behavior and aggregate information appear to affect beliefs we now turn to the relationship between beliefs and behavior. We test for the effect of beliefs on individual choices taking preference types into account. In table 12 we present results of the familiar regression specification. At w2, pro-socials tend to Leave regardless of their belief. The choice of pro-selfs seems to be contingent on their beliefs. At b2, we observe the same pattern although the significance levels

\footnotetext{
${ }^{20}$ Note that this result is in line with Huck and Jehiel (2004).
} 
Table 11: Beliefs and information

\begin{tabular}{lcccccc}
\hline & \multicolumn{3}{c}{ Personal } & & \multicolumn{3}{c}{ Public } \\
& $\mu^{1}$ & $\mu^{2}$ & $\mu^{3}$ & $\mu^{1}$ & $\mu^{2}$ & $\mu^{3}$ \\
\hline \multirow{2}{*}{ Aggregate information } & - & - & - & -0.344 & $1.181^{* * *}$ & $1.137^{* * *}$ \\
& & & & $(0.526)$ & $(0.345)$ & $(0.083)$ \\
\multirow{3}{*}{ Observed behavior } & $0.477^{* *}$ & $0.921^{* * *}$ & $0.397^{* * *}$ & 0.175 & -0.055 & $0.121^{* *}$ \\
& $(0.236)$ & $(0.120)$ & $(0.103)$ & $(0.161)$ & $(0.246)$ & $(0.051)$ \\
$\theta$ & 0.049 & 0.094 & 0.003 & -0.013 & $-0-003$ & 0.056 \\
\multirow{2}{*}{ Constant } & $(0.056)$ & $(0.080)$ & $(0.067)$ & $(0.012)$ & $(0.020)$ & $(0.041)$ \\
& $0.451^{* *}$ & -0.096 & 0.070 & $1.171^{* *}$ & -0.130 & $-0.168^{* * *}$ \\
\multirow{2}{*}{$N$} & $(0.215)$ & $(0.113)$ & $(0.057)$ & $(0.506)$ & $(0.120)$ & $(0.035)$ \\
\hline
\end{tabular}

Notes: the dependent variables $\mu^{x}$ (for $x=1,2,3$ ) are the marginal beliefs that the opponent will play Leave conditionally on reaching the first, second and third decision node respectively, in any round $t$ from 17 to 19 ; to construct every $\mu^{x}$ we pooled data on beliefs of Whites and Blacks; standard errors in parentheses; significance levels are: ${ }^{*} p<0.1 ; * * p<0.05 ;{ }^{* * *} p<0.01$.

of $\theta$ and the interaction term are marginal.

\section{Discussion}

Compared to other experiments on the Centipede game we find a high rate of passing. This might be due to the payoffs structure that we adopt: the progression of payoffs along the game tree is constant and, at every node, the loss in case the opponent does not cooperate is relatively small. Given this payoff structure, we find that ex post information has a substantial positive effect on average payoffs. In particular, public information release increases passing rates at middle nodes, while it does not affect much cooperation at the very last node. As feedbacks inform subjects that passing rates at the last nodes are higher than they expected, beliefs are revised upwards and behavior adapts. The direction of the effect of 
Table 12: Individual behavior and beliefs in the previous round

\begin{tabular}{lccccc}
\hline & w1 & b1 & w2 & b2 & w3 \\
\hline Belief & -0.010 & 0.467 & $0.715^{* * *}$ & $0.747^{* *}$ & 0.339 \\
& $(0.034)$ & $(0.418)$ & $(0.257)$ & $(0.354)$ & $(0.508)$ \\
$\theta$ & 0.012 & 0.508 & $0.619^{*}$ & 0.370 & 0.105 \\
\multirow{2}{*}{ Belief * $\theta$} & $(0.031)$ & $(0.463)$ & $(0.344)^{*}$ & $(0.291)$ & $(0.309)$ \\
& -0.010 & -0.548 & $-0.664^{*}$ & -0.390 & 0.400 \\
Constant & $(0.050)$ & $(0.499)$ & $(0.400)^{*}$ & $(0.475)$ & $(0.750)$ \\
& $1.003^{* * *}$ & 0.569 & 0.338 & 0.289 & $0.315^{*}$ \\
\hline \multirow{2}{*}{$N$} & $(0.022)$ & $(0.387)$ & $(0.221)$ & $(0.197)$ & $(0.191)$ \\
\hline
\end{tabular}

Notes: the dependent variables are the choice (Take (0) or Leave (1)) at each decision node of Blacks and Whites except the last one, in any round $t$ from 17 to 19; the variable Belief is the marginal belief elicited in round $t-1$ that the opponent in round $t$ will play Leave conditionally on reaching his first (w1 or b1), second (w2 or b2) and third (w3) decision node; standard errors in parentheses; significance levels are: ${ }^{*} p<0.1 ;{ }^{* *} p<0.05 ;{ }^{* * *} p<0.01$.

aggregate information on cooperation is not the focus of our paper, though. ${ }^{21} \mathrm{We}$ are indeed more interested in the mechanisms through which different ex post information structures affect behavior of different preference types than on the sign of the effect per se. In the following we look in more detail at the area where behavior in our experiment deviates from what we hypothesized. What could be an explanation for the lack of heterogeneity in PERSONAL-DIRECT?

At first glance it seems puzzling that behavior differs across preference types in PERSONAL-STRATEGY, while in PERSONAL-DIRECT preference types behave quite similarly. Overall, subjects do not cooperate more in PERSONALSTRATEGY than in PERSONAL-DIRECT (see figure 2). Looking closer, we find that pro-socials display different behavioral patterns in the two elicitation

\footnotetext{
${ }^{21}$ Maniadis (2010) shows that the effect of public feedbacks on outcomes varies significantly with the payoff structure. By increasing only the payoff from Leave of the player active at the very last node, the effect of public feedbacks on average payoffs, that is negative in the benchmark (i.e., more unraveling), becomes positive (more cooperation).
} 
methods. First of all, in PERSONAL-STRATEGY they display a passing rate that is larger than in PERSONAL-DIRECT at middle decision nodes (b2 and w3). Secondly, in PERSONAL-DIRECT they respond to their own observations while in PERSONAL-STRATEGY they do not seem sensitive to observed behavior (see w2 and b2 in table 4). Third, while at the individual level in PUBLIC pro-socials significantly react to exogenous feedbacks, the treatment effect of aggregate information provision is larger in DIRECT than in STRATEGY. Indeed, similarly to pro-selfs, prosocials tend to take at later nodes in PUBLIC-DIRECT than in PERSONAL-DIRECT, while in STRATEGY, differently from pro-selfs, pro-socials do not change much their behavior across information treatments. This may be due to the fact that in PERSONAL-STRATEGY prosocials display rather high passing rates at middle nodes, so that access to aggregate information in PUBLIC-STRATEGY adds nothing to their understanding of the opponent's play. All this evidence taken together suggests that the positive effect of social concerns in the decisions to Leave fades more easily in DIRECT than in STRATEGY. We cannot conclude that social preferences have no bite at all in DIRECT, but certainly our preference types (measured based on distributional concerns) seem to affect subjects' strategic reasoning to a smaller extent. We can conjecture that the two structures of play trigger different categories of social preferences. When the game structure is essentially static and subjects are asked to express a choice over terminal nodes (STRATEGY), distributional concerns with respect to payoffs are a natural criterion (in addition to expectations). When the game structure is explicitly interactive and dynamic (DIRECT), besides distributional concerns, other intrinsic motives, induced by emotions, may kick in. ${ }^{22}$ Emotions

\footnotetext{
${ }^{22}$ See Brandts and Charness (2011) for a discussion of the direct response and the strategy method in experiments. According to Brandts and Charness (2011), the direct response method might trigger emotional reactions that are absent in the strategy method. Notice however that in our experiment the direct method and the variant of the strategy method that we adopt do not produce different results at the aggregate level. What changes across methods is the impact of social preferences on behavior.
} 
may be triggered by the fact that in DIRECT subjects observe how their co-player actually played. Hence, subjects who do not have any particular concern for the payoff of a generic other may still be inclined to reciprocate the co-player for leaving the money on the table. Similarly, guilt averse subjects may infer that behind the co-player's choice of passing there is the expectation of being rewarded and so they feel obliged to also pass when it is their turn to move. Thus, there may be subjects classified as pro-selfs, who behave in DIRECT similarly to pro-socials. While these reactions would have a positive effect on the tendency to Leave (of proselfs), the dynamic interaction in DIRECT could also have negative emotional effects. Expectations about the co-player's Leave choice may build up by the exchange of Leave choices at the early nodes. The disappointment by a co-player choosing Take (right after one decided to Leave once more) would consequently be higher in DIRECT than in STRATEGY. Such unfulfilled expectations would result in negative emotions like anger. If experienced often enough such unreturned trust would lead to a higher tendency to avoid getting disappointed, that is, to choose Take before the co-player could. Naturally, subjects who exhibit a high tendency to Leave (at middle and late nodes) are much more prone to encounter a co-player who decides to Take and, in turn, their chances are higher to suffer from this negative effect.

Our interpretation based on the different emotional impact of DIRECT vs. STRATEGY is in line with behavior at the last node. In DIRECT-PERSONAL, the only decision node where behavior differs significantly across preference types is b3. At the final node of the game there are no strategic reasons for choosing Leave, hence, cooperation at this point can only be due to social preferences. In principle, Leave at b3 may be justified both by distributional concerns and by the willingness to reciprocate the co-player for reaching the final node. We find that the preference type has a significant effect at this node both in PERSONAL-DIRECT and PUBLIC-DIRECT, while it does not have any effect in PERSONAL-STRATEGY and only a small effect in PUBLIC-STRATEGY. That is, in STRATEGY prosocial Blacks have a higher tendency than proselfs to Leave up to their third node, 
but among the Blacks who decide to do so there is no difference across preference types in passing rates at the third node. This indirectly suggests that the higher tendency to Leave by Black prosocials at the last node in DIRECT might be due to direct reciprocity towards the co-player who allowed them to reach that node. ${ }^{23}$ Notice however that we cannot fully exclude the alternative interpretation that in DIRECT distributional concerns emerge only at the last node when the payoff allocation becomes focal and strategic reasoning is muted.

\section{Conclusion}

Heterogeneous behavior is a common finding in the Centipede game. We study experimentally whether this heterogeneity of behavior results from a learning process of individuals with different preference types (more and less prosocial) and coarse information regarding the opponent's past behavior. Our design implements three different levels of ex post information structure: when subjects' knowledge is limited to their own experiences (PERSONAL), when subjects get information about others' past average choices at each node (PUBLIC-DIRECT) and when they get information about others' past average strategies (PUBLIC-STRATEGY).

Results from the experiment are largely in line with our hypotheses. When feedback is limited to own experiences (PERSONAL), we find heterogeneous behavior across preference types as prosocials tend to stop at later nodes than proselfs in PERSONAL-STRATEGY (albeit we find no difference in PERSONAL-DIRECT). When feedback about aggregate choices is provided (PUBLIC), proselfs tend to

\footnotetext{
${ }^{23}$ In contrast, the direct reciprocity interpretation suitable for DIRECT does not apply to the choice of Leave at b3 in STRATEGY. Indeed, in STRATEGY subjects choose ex ante their preferred terminal nodes given their predictions about the opponent's behavior and not after observing his actual play, as it occurs in DIRECT. Chen and Schonger (2015) provide a theoretical interpretation of the different implications on outcomes of eliciting behavior with the direct or the strategy method which is based on the intuition that the commitment to a strategy is costly.
} 
stop at later nodes than in PERSONAL leading to more homogeneity of behavior across preference types. Finally, the extent of providing aggregate information (more comprehensive in PUBLIC-STRATEGY than in PUBLIC-DIRECT) has a positive effect on the tendency to Leave. Also this effect can be attributed to pro-selfs.Finally, first round choices and initial beliefs indicate that heterogeneous behavior indeed originates from preferences. Since the very beginning of the learning process, pro-socials display a higher passing rate than pro-selfs and tend to have higher expectations about the opponent's behavior, although high beliefs can compensate for the preferences of selfish types.

Our study unifies two previous approaches attempting to explain heterogeneity of behavior and absence of unraveling. We assume that the presence of prosocial types, as suggested by McKelvey and Palfrey (1992), as well as strategic uncertainty, as suggested by Cox and James (2012), matter and in addition the interaction between the two. In particular, our results suggest that equilibrium models that aim at interpreting behavior in the Centipede game cannot disregard that both social preferences and prediction errors matter and that prediction errors, and thus information feedbacks, affect behavior of different preference types to different extents.

Further investigation of the mechanisms through which social concerns affect strategic reasoning depending on the elicitation method may prove a fruitful avenue for future research. Our results show that, at the aggregate level, long run outcomes as well as consequences of different ex post information structures are similar across different structures of play (direct response versus strategy method). Existing studies that investigate whether the direct and the strategy method deliver different outcomes provide no theoretical interpretation that could account for the different impact of preferences on middle nodes behavior that we find. 


\section{Acknowledgments}

We are grateful to the Max Planck Institute of Economics, Jena, for financial support. We thank Pierpaolo Battigalli, Lorenzo Cappellari, Paolo Crosetto, Anna De Paoli, Werner Güth, Zacharias Maniadis, Natalia Montinari, Luca Stanca and attendants of the ESA European Conference 2012 (Cologne), of UECE 2012 (Lisbon), of the Game Theory at the Universities of Milano III 2013 workshop (Milano), and seminar participants at IMW 2013 (Bielefeld) for useful suggestions. The usual disclaimer applies.

\section{References}

Battigalli, Pierpaolo. 1987. "Comportamento razionale ed equilibrio nei giochi e nelle situazioni sociali." unpublished undergraduate dissertation, Bocconi University, Milano.

Battigalli, Pierpaolo, and Danilo Guaitoli. 1997. Conjectural equilibria and rationalizability in a game with incomplete information. Springer.

Battigalli, Pierpaolo, Simone Cerreia-Vioglio, Fabio Maccheroni, and Massimo Marinacci. 2015. "Self-confirming equilibrium and model uncertainty." The American Economic Review, 105(2): 646-677.

Brandts, J., and G. Charness. 2011. "The strategy versus the direct-response method: A first survey of experimental comparisons." Experimental Economics, 14(3): 375-398.

Brown, George W. 1951. "Iterative solution of games by fictitious play." Activity analysis of production and allocation, 13(1): 374-376.

Chen, Daniel L, and Martin Schonger. 2015. "A Theory of Experiments: Invariance of Equilibrium to the Strategy Method and Implications for Social Preferences." mimeo. 
Cox, James C, and Duncan James. 2012. "Clocks and Trees: Isomorphic Dutch Auctions and Centipede Games." Econometrica, 80(2): 883-903.

Dekel, Eddie, Drew Fudenberg, and David K Levine. 2004. "Learning to play Bayesian games." Games and Economic Behavior, 46(2): 282-303.

Engelmann, Dirk, and Martin Strobel. 2012. "Deconstruction and Reconstruction of an Anomaly." Games and Economic Behavior, 76(2): 678-689.

Fischbacher, Urs. 2007. "z-Tree: Zurich toolbox for ready-made economic experiments." Experimental Economics, 10(2): 171-178.

Fudenberg, Drew, and David K Levine. 1993a. "Self-confirming equilibrium." Econometrica, 523-545.

Fudenberg, Drew, and David K Levine. 1993b. "Steady state learning and Nash equilibrium." Econometrica, 547-573.

Gamba, Astrid. 2013. "Learning and evolution of altruistic preferences in the Centipede Game." Journal of Economic Behavior \& Organization, 85: 112-117.

Greiner, Ben. 2004. "The Online Recruitment System ORSEE 2.0 - A Guide for the Organization of Experiments in Economics." Department of Economics, University of Cologne mimeo.

Huck, Steffen, and Philippe Jehiel. 2004. "Public statistics and private experience: varying feedback information in a take or pass game." ESRC Centre for Economic Learning and Social Evolution working paper.

Jehiel, Philippe. 2005. "Analogy-based expectation equilibrium." Journal of Economic Theory, 123(2): 81-104.

Maniadis, Zacharias. 2010. "Aggregate information and the centipede game: a theoretical and experimental study." UCLA Department of Economics Working Paper. 
McKelvey, Richard D, and Thomas R Palfrey. 1992. "An experimental study of the centipede game." Econometrica, 803-836.

Murphy, Ryan O, Kurt A Ackermann, and Michel Handgraaf. 2011. "Measuring social value orientation." Judgment and Decision Making, 6(8): 771781.

Rosenthal, Robert W. 1981. "Games of perfect information, predatory pricing and the chain-store paradox." Journal of Economic Theory, 25(1): 92-100.

Ross, Lee, David Greene, and Pamela House. 1977. "The false consensus effect: An egocentric bias in social perception and attribution processes." Journal of experimental social psychology, 13(3): 279-301.

Selten, R. 1967. "Die Strategiemethode zur Erforschung des eingeschränkt rationalen Verhaltens im Rahmen eines Oligopolexperiments." Beiträge zur experimentellen Wirtschaftsforschung, 1: 136-168.

\section{Appendix}

\section{A. Social Value Orientation (SVO)}

The SVO slider measure (Murphy, Ackermann and Handgraaf, 2011) consists of six primary items and nine optional ones. All items have the same general form. In each item subjects face a resource allocation choice over a well defined continuum of joint payoffs (self and other). ${ }^{24}$ In contrast to the simple categorization of previous SVO measures the slider measure yields a continuous measure based on choices in the six primary items (the SVO angle), see figure 3 for the distribution among our participants.

\footnotetext{
${ }^{24}$ The social value orientation literature distinguishes four idealized social orientations among individuals: altruistic, pro-social, individualistic, and competitive. The six primary items represent continuous choices between the payoff pairs that represent these four types. One item, for instance, features the trade-off between the perfectly altruistic choice of $(50,100)$ and the perfectly individualistic choice of $(100,50)$. Besides these extreme values there are always seven in-between allocations to allow for intermediate choices.
} 


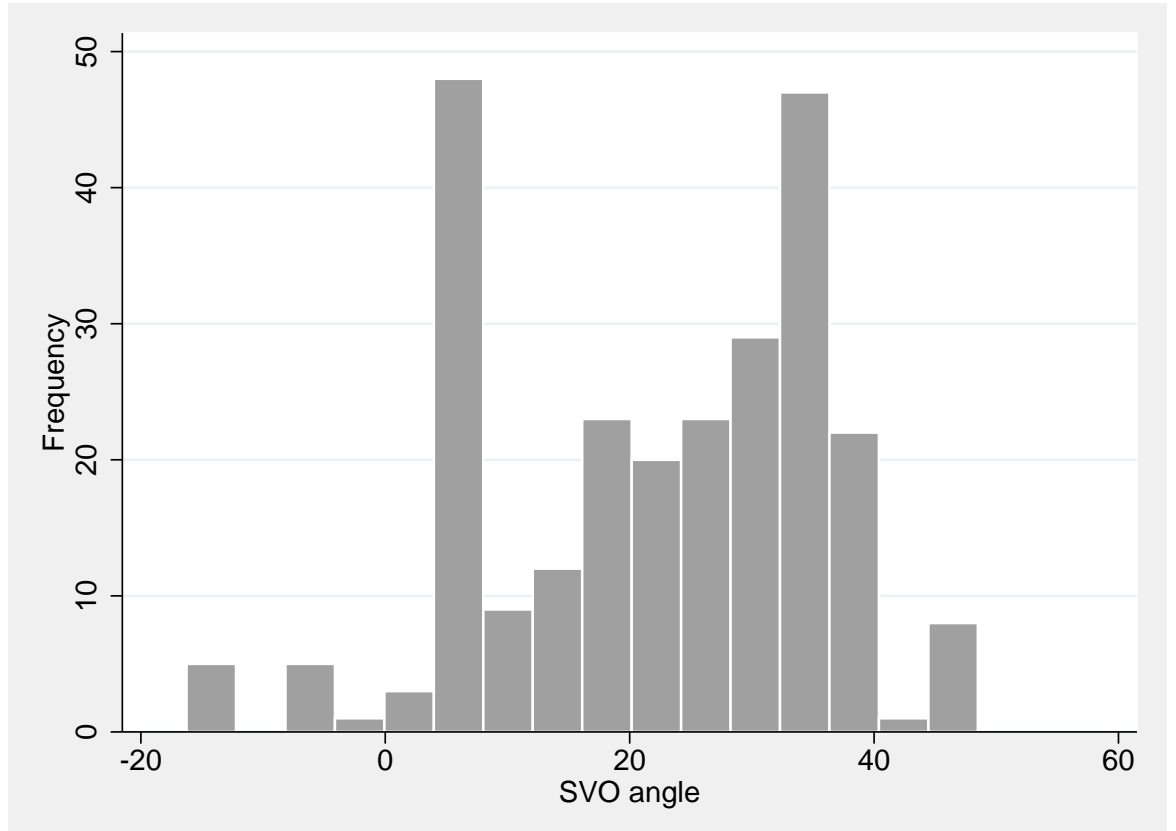

Figure 3: Distribution of Social Value Orientation scores (slider measure)

\section{B. Mini trust game}

In the mini trust game, played in part 1 of the experiment, player A has to decide whether to invest an endowment of 6 experimental currency units (ECU), by sending it to player B (action $a_{2}$ ) or keep the money for himself (action $a_{1}$ ). If A sends the 6 ECU, the total amount of money available to the players increases and it is B's turn to move, while if A keeps the 6 ECU, the game ends. In the latter case, A has also to decide on a (small) voluntary transfer $t$ to $\mathrm{B}, t \in\{0,0.5,1,1.5,2\}$, so that A gets $6-t$ ECU, while B gets $t$ ECU. This transfer represents a sort of compensation to $\mathrm{B}$ for stopping the game. If, instead, A sends the money to B, $\mathrm{B}$ has to decide whether to further invest the augmented some of money (action $b_{2}$ ) or to keep most of it (action $b_{1}$ ). If $\mathrm{B}$ chooses $b_{1}$, he gets 6 ECU, while A gets 2 ECU. If, instead, B further invests, the total amount of money available to the players increases, but B only gets 4 ECU out of it, while A gets 8 ECU. Behavior is elicited via strategy method: participants are first requested to make a decision in B's shoes and then in A's shoes. Participants who chose $a_{1}$ have also to choose the transfer $t$. They are assigned either role A or B, they are anonymously matched 
with another participant in the same session and paid the monetary outcomes generated by the strategy profile they adopted (at the end of the experiment). The mini trust game is illustrated in Figure 4.

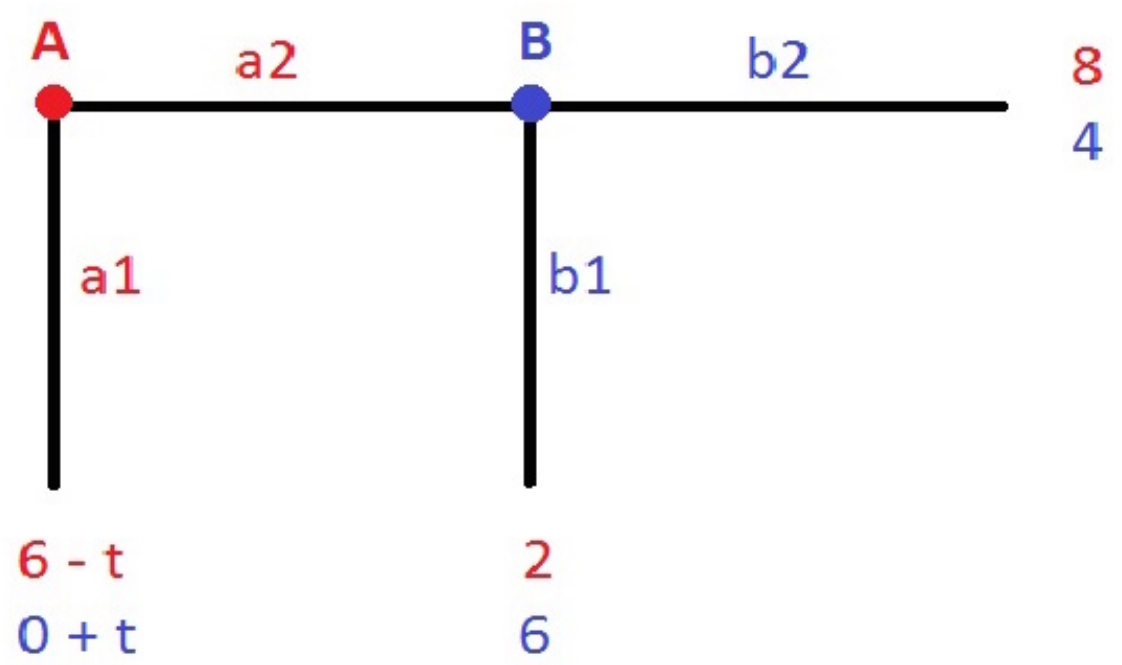

Figure 4: The mini trust Game

In the mini trust game, $37,1 \%$ of our participants chose $b_{2}$ in B's role, while $29,3 \%$ chose $a_{2}$ in A's role and among those who chose $a_{1} 46,4 \%$ chose a transfer larger than zero.

\section{Beliefs at round 40}



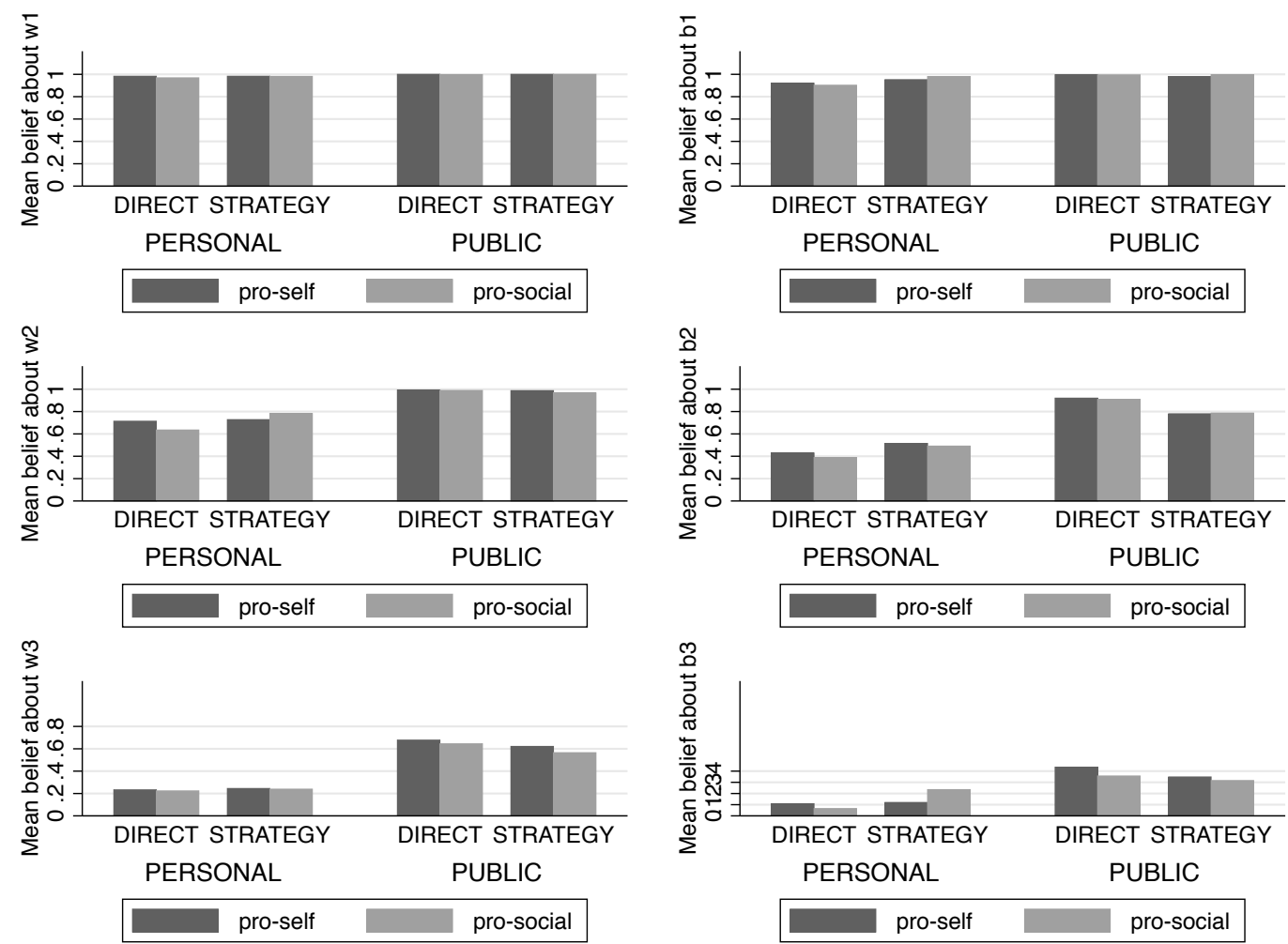

Figure 5: Each of the 6 graphs represents the mean of marginal subjective probabilities (elicited in round 40) that the opponent will play Leave at respective decision nodes, by information treatment, by elicitation method and by preference type at each decision node of the game.

\section{Experimental Instructions (translated from German)}




\section{Instructions}

Welcome and thank you for your participation! In this experiment you can earn money depending on your decisions and those of the other participants. It is therefore very important that you read these instructions thoroughly.

Please note that talking to other participants is forbidden during the entire experiment. If you have any questions, please raise your hand. An experimenter will then approach you and answer your questions in private. Please, by no means ask your questions aloud!

If you do not follow these rules we are forced to terminate the experiment. Please turn off your mobile phones now.

\section{General procedure}

The experiment will take 90 minutes. It consists of two parts. The procedure of part one will be explained to you in the following. The instructions for the second part will be handed to you after the first part. You can earn money in both parts of the experiment. The sum will be paid to you in the end.

The separate decision situations will as well be explained to you briefly on the screen.

Your payoffs will be indicated in ECU (Experimental Currency Units), where

$$
1 \mathrm{ECU}=0.75 \mathrm{EURO}
$$

Your payoff depends on your decisions and possibly those of the other participants. At the end of the session your payoff will be converted from ECU to EURO and paid to you in cash. You receive a basic fee of 2.50 EURO for coming. For filling in the online questionnaire prior to the experiment you receive another 3 EURO.

After filling in a final questionnaire the experiment ends and you receive your payment.

Overview of the experiment session:

- Reading the instructions

- Decision making part 1

- Instructions for part 2; Answering control questions (online)

- Part 2 of the experiment

- Questionnaire

- Payment and end of the experiment 


\section{Details on part 1}

In the first part of the experiment participants interact in groups of two. The participants will be named participant $A$ and participant $B$. We ask you for your decisions as participant $A$ as well as $B$. It is therefore very important that you make yourself familiar with both roles.

At the end of the experiment, the computer assigns the roles at random to you and the other participant. Your payoff from this part of the experiment depends on your decisions and those of one other participant. You will be informed about the payoffs at the end of the experiment (after part 2).

In this part participant A makes the first decision. She can choose a1 or a2.

- Choosing a1 means, that participant A has $6 \mathrm{ECU}$ at her disposal. Participant A can further choose to make a transfer.

This transfer $t$ can consist of $0 \mathrm{ECU}, 0.5 \mathrm{ECU}, 1 \mathrm{ECU}, 1.5 \mathrm{ECU}$ or $2 \mathrm{ECU}$. Transfer $\mathrm{t}$ will be subtracted from A's payoff and added to B's payoff. If participant A chooses a1, A receives at least $4 \mathrm{ECU}$ (and B $2 \mathrm{ECU}$ ) and at max $6 \mathrm{ECU}$ (and B $0 \mathrm{ECU}$ ).

- If participant $A$ chooses option a2, the payoffs will be determined by participant $B$.

$B$ can choose among option b1 and b2:

- Choosing b1 means that participant A receives $2 \mathrm{ECU}$ and participant $\mathrm{B}$ receives $6 \mathrm{ECU}$.

- Choosing b2 means that participant A receives $8 \mathrm{ECU}$ and participant $\mathrm{B}$ receives $4 \mathrm{ECU}$.

Throughout the experiment, participant $B$ always has to indicate his choice, independent of the choice of participant $A$.

The following diagram illustrates the game and the resulting payoffs:

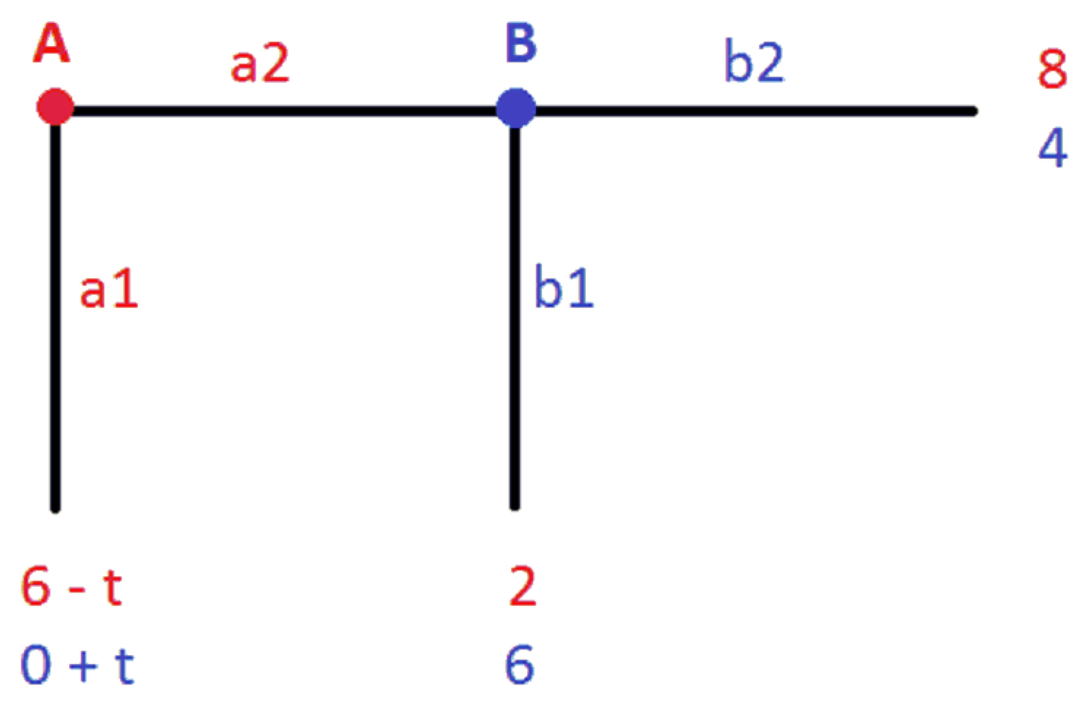




\section{Details on part 2}

This part consists of 40 rounds. In every round two participants interact. They will be named participant $\mathrm{W}$ and participant $\mathrm{S}$. The role of $\mathrm{W}$ or $\mathrm{S}$ will be assigned to you randomly at the beginning of the experiment. It is therefore decisive that you make yourself familiar with both roles.

During the first 15 rounds a participant you haven't interacted with before will be assigned to you. This participant has not interacted with participants you have interacted with before.

In the following rounds, the participants will be assigned to each other randomly. You will never get to know the identity of the other participants.

\section{Decision situation in one round}

In each round participant $\mathrm{W}$ and $\mathrm{S}$ make decisions in turns.

- The first decision of a round is always made by participant W.

- You can either choose TAKE or LEAVE.

- If you pick TAKE, the round ends.

- If you pick LEAVE it is the other participant's turn (unless you are in the last decision node).

The payoffs are calculated as follows:

- If participant $\mathrm{W}$ chooses TAKE in node 1 , she $\mathrm{W}$ receives 5 and participant $\mathrm{S}$ receives 1.

- If participant $\mathrm{W}$ chooses LEAVE in node 1 and...

- If participant $S$ chooses TAKE in node 2, then $W$ receives 3 and $S$ receives 7 .

- If participant $S$ chooses LEAVE in node 2 , and...

- If participant $\mathrm{W}$ chooses TAKE in node 3 , then $\mathrm{W}$ receives 9 and $\mathrm{S}$ receives 5 .

- If participant $W$ chooses LEAVE in node 3 and...

- If participant Schooses TAKE in node 4, then $\mathrm{W}$ receives 7 and $S$ receives 11.

- If participant $S$ chooses LEAVE in node 4 , and ...

- if participant $\mathrm{W}$ chooses TAKE in node 5 , then $\mathrm{W}$ receives 13 and $S$ receives 9

- If participant $W$ chooses LEAVE in node 5 and ...

- If participant $S$ chooses TAKE in node 6 , then $W$ receives 11 and $S$ receives 15 .

- If participant $S$ chooses LEAVE in node 6 , then $W$ receives 17 and $S$ receives 13.

STRATEGY condition \{

IMPORTANT: You will always be asked for your decisions at all three nodes no matter what the other participant chose (for $W$ these are nodes 1, 3, 5; for $S$ these are nodes 2, 4, 6). 
Thus, you will be asked in advance whether you choose TAKE or LEAVE at each node. The following four options contain the relevant choices for you. In each round you can decide whether you want to ...

- TAKE at your first node. This option is referred to as:

$>$ TAKE at node 1 (for W), TAKE at node 2 (for $S$ )

- LEAVE at your first node and TAKE at the second one.

$>$ TAKE at node 3 (for W), TAKE at node 4 (for $S$ )

- LEAVE at the first two nodes and TAKE at the third.

LEAVE at node 5 (for W), TAKE at node 6 (for S)

- LEAVE at all of your nodes.

- LEAVE at all nodes (for W and S)

\}

The following graph provides an overview of one round (from participant W's perspective):

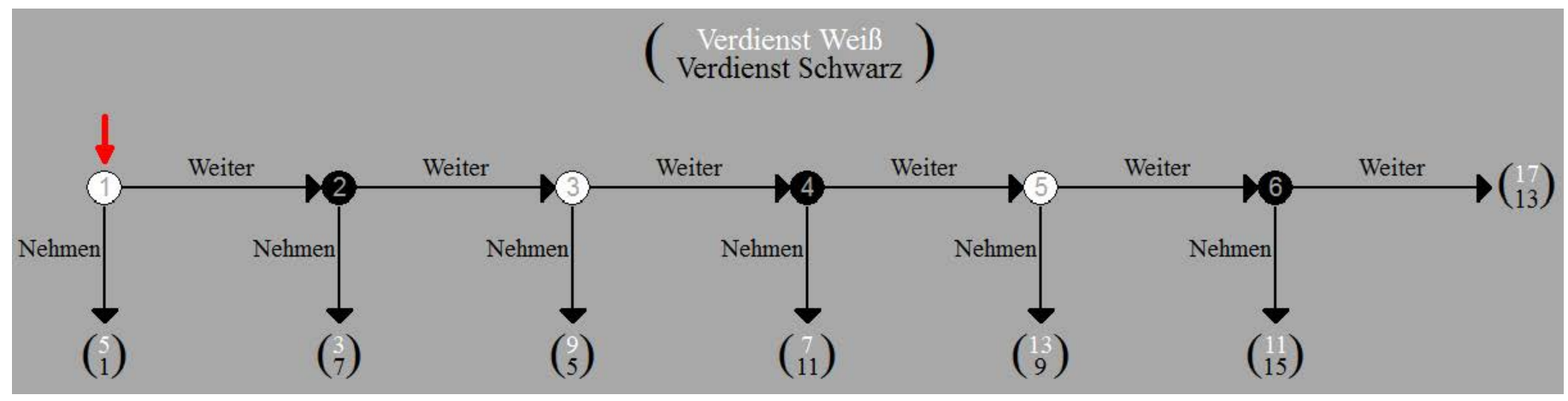

In the course of a round, the arrow indicates where a decision has to be made.

The following graph provides an example for the decision of participant $\mathrm{S}$ in node 4:

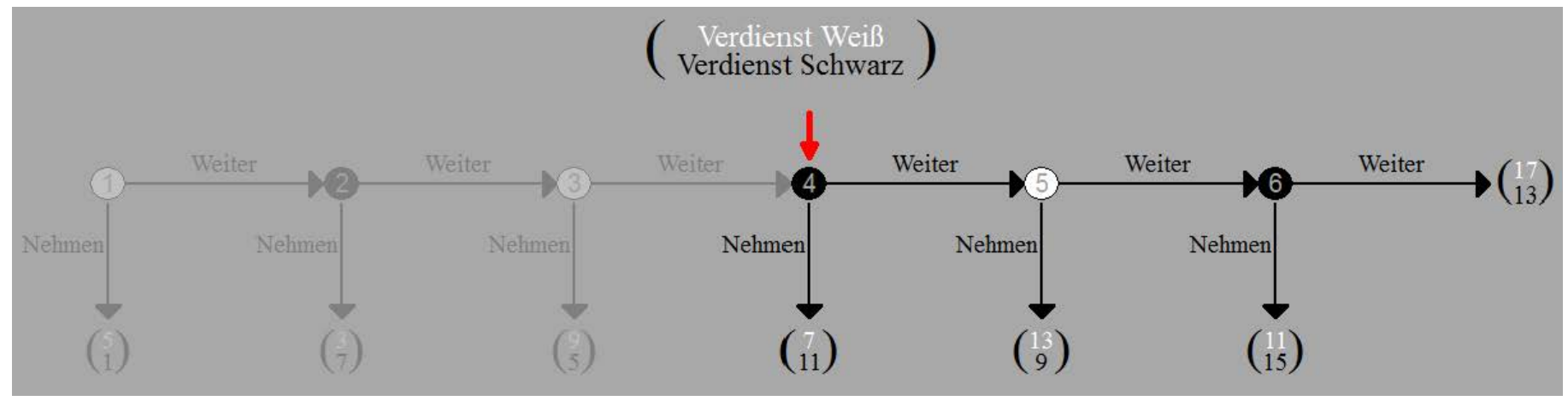

STRATEGY condition \{

The payoffs of one round result from the options chosen by the two interacting participants assigned to each other. If for example

- Participant W chooses option ,Take at node 1', then the payoff is independent of the choice of participant $S$ and is in any case $5 \mathrm{ECU}$ for $\mathrm{W}$ and $1 \mathrm{ECU}$ for $\mathrm{S}$.

- If both participants choose ,LEAVE at all nodes', the payoffs are 17 ECU for W and 13 ECU for $S$. 
- If participant W chooses, Take at node 5' and $S$ chooses, Take at node 4 " then the payoffs are $7 \mathrm{ECU}$ for $\mathrm{W}$ and $11 \mathrm{ECU}$ for $\mathrm{S}$.

At the end of each round you will see what you and the participant assigned to you have earned in this round.

\section{PUBLIC condition \{}

\section{Information about the decisions of the other participants (W and $S$ respectively)}

Furthermore, after you are informed how much you earned you will see how many of the other participants (in percent) have chosen DIRECT condition \{LEAVE at every node\} STRATEGY condition \{the four options\}. As participant $W$ you will be informed about the decisions of the participants S. As participant S you will be informed about the decisions of the participants $\mathrm{W}$. Then, the next round starts.

\}

\section{Overview of one round:}

1. Participant $\mathrm{W}$ makes her choice at node 1.

2. Possibly: Participant S makes her choice at node 2.

3. Possibly: Participant W makes her choice at node 3.

4. Possibly: Participant $S$ makes her choice at node 4.

5. Possibly: Participant $W$ makes her choice at node 5.

6. Possibly: Participant S makes her choice at node 6.

7. Overview of the payoffs of this round.

8. Information about the decisions of the other participants (W or S).

Please note that is forbidden to make notes during the game. You will be informed about your payoffs at the end of the experiment.

\section{Payment}

The earnings in the second part will be calculated as explained above. However, only two of the 40 rounds will be relevant for your payoff (one of the 20 first, and one of the 20 last rounds).

These rounds will be determined by chance at the end of the experiment. Furthermore, you receive your payoff of the first part and 3 Euro for completing the online questionnaire.

Your final payoff will be paid in cash to you at the end of the experiment, i.e. after completing the final questionnaire. 